\title{
Recent Advances in the Quest for Treatment and Management of Alzheimer and Other Dementia
}

\author{
Sameena E. Tanwir, Ajay Kumar* \\ School of Science, Technology and Environment, Universidad Ana G. Mendez, San Juan, PR, USA \\ Email: ^ajkumar@suagm.edu
}

How to cite this paper: Tanwir, S.E. and Kumar, A. (2019) Recent Advances in the Quest for Treatment and Management of Alzheimer and Other Dementia. Open Journal of Medicinal Chemistry, 9, 1-35. https://doi.org/10.4236/ojmc.2019.91001

Received: December 5, 2018

Accepted: March 10, 2019

Published: March 13, 2019

Copyright $\odot 2019$ by author(s) and Scientific Research Publishing Inc. This work is licensed under the Creative Commons Attribution International License (CC BY 4.0).

http://creativecommons.org/licenses/by/4.0/

\section{(c) (i) Open Access}

\begin{abstract}
Alzheimer's disease $(\mathrm{AD})$ is a neurodegenerative disease distinguished by progressive cognitive deterioration along with declining activities of daily living and behavioral changes. It is the commonest type of pre-senile and senile dementia. Many new therapeutic strategies have been developed in the last few years. We aimed at reviewing the evidence supporting these new therapeutic targets, including anti-amyloid and anti-Tau strategies. This review is focused on important future direction in investigation of potential therapeutic targets for $\mathrm{AD}$ drug discovery. Medical advances have improved treatment of many diseases but still there is a need to establish new tools for early diagnosis of AD. A thorough comprehensive understanding of the unexplored mechanism can ameliorate the diagnostic and therapeutic management of $\mathrm{AD}$. There have been several disease-modifying therapeutic strategies for $\mathrm{AD}$ in the last few years and are presently at various phases of investigation. Few of them have shown promising results, but their safety and efficacy need to be further explored.
\end{abstract}

\section{Keywords}

Alzheimer, $\beta$ Amyloid, Tau, Acetylcholinesterase, Amyloid Precursor Protein, Plaques, Tangles, Neurodegeneration

\section{Introduction}

Dementia is used to describe a broad range of symptoms that impact memory, thoughts, performance of everyday routine activities, and difficulty in learning and communication abilities. The most common type of dementia is Alzheimer's Disease $(\mathrm{AD})$ which gets worse with time; irreversible dementia is becom- 


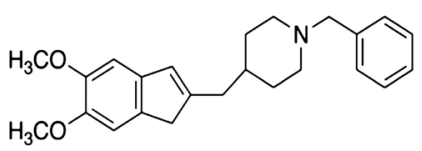

Donepezil ing a major threat for the aging people [1]. AD is considered as the sixth leading cause of death in USA. It is the only disease in America in the top ten that cannot be prevented, cured or slowed. It causes the degeneration of loss of neurons in the brain particularly in the cortex. Despite decades of research on the etiology, the precise cause appears to be unclear. $\mathrm{AD}$ destructs the patients mind, makes significant burdens for their families and caregivers and outlays the United States billions of dollars every year. According to the Alzheimer's Association today, more than 5 million Americans are living with Alzheimer's disease. As per estimations Alzheimer's and other dementias may cost the U.S. health care system for more than $\$ 259$ billion during 2017, which will potentially increase approximately 4 -fold to $\$ 1.1$ trillion by 2050 [2]. The early stage of $\mathrm{AD}$ short-term memory loss appears [3], as it progresses through the different stages of dementia, cognitive impairment such as forgetfulness with daily activities, remembering names of familiar people or thing becomes increasingly noticeable and severe [4] [5].

Current approaches for drug development are basically therapeutic. Due to the complex etiology of $\mathrm{AD}$, its pathogenesis has not been fully interpreted, and numerous pathogenesis hypotheses for $\mathrm{AD}$ have been explained, such as cholinergic hypothesis [6], amyloid cascade hypothesis [7] [8], oxidative stress hypothesis [9], and metal dyshomeostasis hypothesis [10] [11]. Despite continuous efforts towards unraveling the brain complexities and recognizing the keystones of Alzheimer's, the effective treatment foundation remains an unnerving challenge [12]. There is currently no cure to stop or reverse the advancement of AD. However, medications presently available treat the disease symptoms like memory loss, confusion and problems with thinking. Nevertheless, there are presently five FDA-approved medications Donepezil (Aricept), Galantamine (Reminyl), Rivastigmine (Exelon), Tacrine (Cognex) and Memantine (Namenda) which are available that temporarily improve symptoms, but the benefits are not so potent and none is capable to halt the progression of this disease (Figure 1) [13] [14]. This review summarizes the therapeutic agents discovered so far, which could lead to the development of an effective drug for AD.

General structure of the review is:

1) Etiology of Alzheimer's Disease;

2) Current strategy for Alzheimer's Disease treatment;

3) Strategies in drug discovery for Alzheimer's Disease;<smiles>COc1ccc2c3c1OC1(CCN(C)C2)CC(O)C=CC31</smiles>

Tacrine<smiles>CC1(C)CC2CCC1CC2N</smiles><smiles>CCN(C)C(=O)Oc1cccc(C(C)N(C)C)c1</smiles>

Figure 1. Medications approved by FDA for AD treatment. 
4) Conclusion.

\section{Etiology}

The initiation of pathogenic process is explained by the formation of amyloid plaques, which starts either because of mutations in the amyloid precursor protein (APP), or due to other mutations and environmental factors [7]. These changes lead to the formation of amyloidogenic peptides that first aggregate into oligomers, which can interfere with synaptic neurotransmission (e.g. cholinergic neurotransmission), and then into amyloid plaques, which are thought to cause intracellular metabolic alterations that lead to the hyperphosphorylation of tau proteins [15]. Thus hyperphosphorylated tau proteins aggregate to form neurofibrillary tangles that alter intracellular metabolism to a sufficient degree to cause neuronal death. Both $\beta$-amyloid plaques and neurofibrillary tangles are thought to cause an excessive release of glutamate in certain cortical and sub-cortical structures [16] [17] [18] that can lead to neuronal death through $\mathrm{N}$-methyl-D-aspartate (NMDA) receptor mediated excitotoxicity [19].

\section{Current Strategy}

Present research to treat $\mathrm{AD}$ is focused on either to impede or slow down disease progression by directing one or more of the brain changes instigated by $\mathrm{AD}$. These targets of treatment are $\beta$-amyloid plaques that occur between the cells of the nerve, tangles of tau protein that damage and kill cells of the brain by disabling the nerve transport system and a receptor that decreases a neurotransmitter required for the brain to think and function normally. Potential medications also intend to decrease neuro-inflammation that is accompanied with Alzheimer's and targets the immune system to empower it to fight the disease.

Intensifying the central cholinergic movement and ameliorating acetylcholine level in the brain, for example, by prohibiting the activity of acetylcholinesterase (AChE) have been believed to be a powerful approach AD therapy [20] [21]. Presently, the first-line drugs for AD treatment are primarily AChE inhibitors such as donepezil, rivastigmine, galantamine, and huperzine A (Hup A, approved by CFDA [13] [22]. These drugs functions only to enhance the memory and cognitive capabilities of $\mathrm{AD}$ patients but do not serve as curative treatment [23] [24].

\section{Strategies in Drug Discovery for Alzheimer's}

\subsection{Biomarkers}

A biomarker is a measurable indicator of some biological or pathological state or condition that is objectively measured to evaluate normal biological or pathological processes. They can be used for diagnosis as well as monitoring the success of a therapy (Figure 2). Present diagnostic techniques for $\mathrm{AD}$ are quiet expensive-magnetic resonance imaging (MRI) or positron emission tomography (PET), invasive cerebrospinal fluid (CSF) biomarkers, genetic markers, serum 


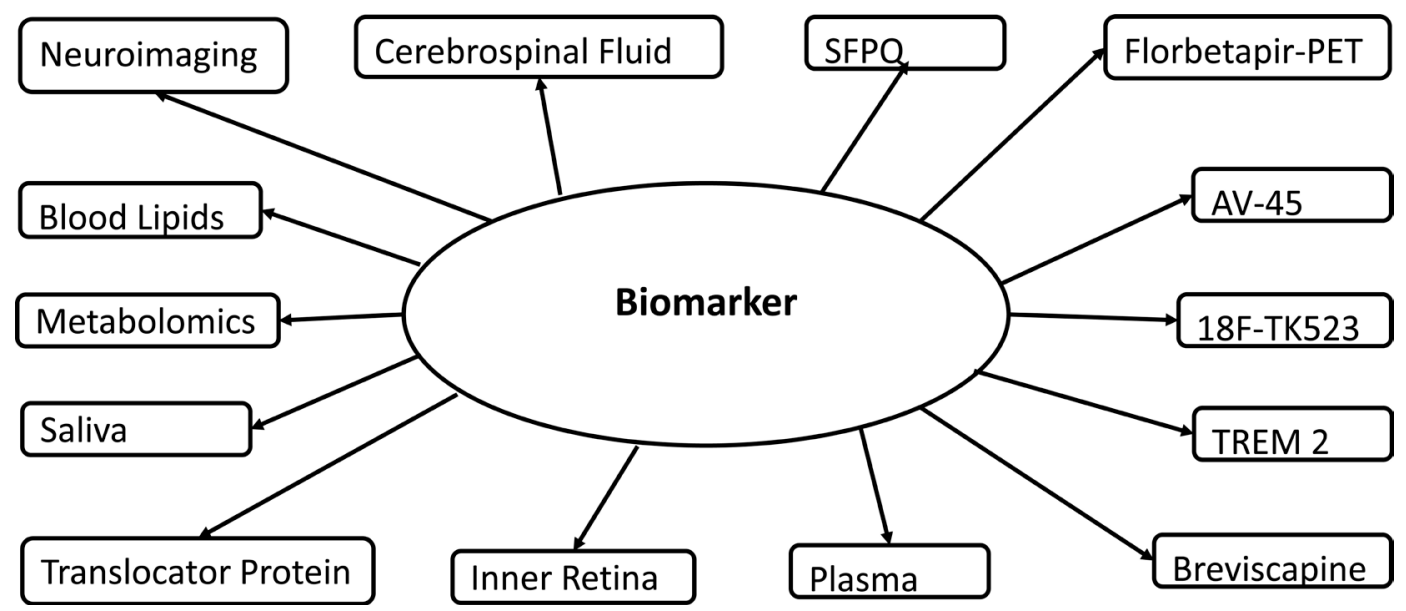

Figure 2. Various biomarkers used in diagnosis of AD.

amyloid within significant specificity and reactivity [25]. However, neuropsychological analysis is considered to be the "gold standard" for pre-mortem detection of $\mathrm{AD}$ [26], but the screening is tedious, and may demand manifold assessment.

Most of the $\mathrm{AD}$ drug development relevant biomarkers presently used are brain imaging, plasma and cerebrospinal fluid (CSF) measures; microarray and spectroscopic examination of multiple genes, proteins, lipids, metabolites. Florbetapir-PET (an imaging agent which has high binding specificity for $\beta$ amyloid) images demonstrates that amyloid- $\beta$ load associates with the cognitive function [27]. Another biomarker $\mathrm{A} \beta$ amyloid can also be analyzed using commercially available imaging agent (AV-45), for further research to understand $\mathrm{AD}$; but still there is no imaging agent commercially available for tau. However, Victor Villemagne's research group is engaged in developing a tau imaging agent 18F-THK523 in patients [27] with Alzheimer and Jeff Kuret is also working on biomarkers for tau imaging for early analysis, differential analysis, and monitoring response to various treatments but selectivity and the binding potential are the key challenges in the development of tau imaging agents. In the frontotemporal dementia, enhanced sensitivity of a TDP-43 was observed during Cerebro Spinal Fluid (CSF) measurement [27]. Neuroimaging and CSF measures of $\beta$-amyloid and neuronal injury demonstrates the importance of the heterogeneity of the definition of neuronal injury, and has significant consequences for clinical trials exploiting biomarkers as substitute endpoint measures [28].

Other major biomarkers developed so far include blood lipids [29], saliva and metabolomics [30], amyloid blood biomarker [31] [32] [33] [34], retinal ganglion cell-inner plexiform layer (GCIPL) and nerve fiber layer (NFL) [35]. Plasma biomarkers have also been found to be very helpful in the detection of $\mathrm{AD}$ [35]. These biomarkers are economic and scalability bonus over existing techniques, facilitating broader clinical approach and productive population screening. Several proteins have been reported to play a significant role in the early detection of $\mathrm{AD}$. A18kDatranslocator protein (TSPO) is known to have a promi- 
nent role in neuroinflammation in dementia pathogenesis and can aid in monitoring disease succession [36]. Another major protein Splicing factor prolineand glutamine-rich (SFPQ) which aids in transcription, pre-mRNA splicing, and DNA damage repair, was found to be dysregulated and dislocated in the development of AD and FTD [37]. Modifications in extracellular matrix proteins ameliorate hippocampal IL6 level and iron in the initial phases of AD and show inflammation-mediated iron dyshomeostasis in the initial phases of neurodegeneration. Besides, the level of iron in the hippocampus was calculated by preliminary coupled plasma-mass spectrometry as IL6 is cited in many studies to take part in iron homeostasis and inflammation and known to be elevated in 5XFAD mice hippocampus [38]. Further, Flavonoids-breviscapine biomarkers were investigated and were found to enhance the learning and memory deficits of $\mathrm{AD}$ mice chiefly by regulating phospholipids metabolism, promoting level of serotonin and reducing cholesterols content in vivo [39]. Noncoding MicroRNA (miR)-34a acts as a promising biomarker for early detection and intervention which contribute to the pathological development of $\mathrm{AD}$ [40] [41].

\subsection{Multi-Target-Directed Ligand (MTDL) Design Strategy}

Multi-target-directed-ligands (MTDLs) are found to be an innovative form of polypharmacology, which are compounds that influence two or more biological targets and processes [42]. This strategy has evolved vigorously over the past few years, mainly in the context of multifactorial diseases such as AD [43] [44] [45] [46]. A variety of promising multifunctional anti-AD molecules has been developed and synthesized by incorporating chemical fragments accountable for interaction with desirable biological targets [47]-[52]. Further MTDL for AD has been developed with multifunctional roles such as antioxidant property, blood-brain barrier penetration, biometal chelation, $\mathrm{A} \beta$ aggregation modulation and neurotrophic and neuroprotective properties [53]. It also revealed hippocampal cell proliferation activity in living adult mice. The role of ASS234 was identified as multi-target directed compound for AD [54]. Presently, the most effective therapeutic strategy for drug designing for $\mathrm{AD}$ is aiming the cholinergic system. It has been proposed that the decline of acetylcholine (ACh) level causes the cognitive and memory deficits [55] [56] [57]. Hence, targeting cholinergic function by preventing cholinesterase's (ChEs), which control the hydrolysis of $\mathrm{ACh}$, is valuable for the treatment of $\mathrm{AD}$ [58] [59]. Two types of ChEs, exits namely, acetylcholinesterase (AChE) and butyrylcholinesterase (BuChE). Normally, AChE is a ruling factor for ACh metabolism (80\%), thus, acetylcholinesterase inhibitors (AChEIs) can proficiently stops the hydrolysis of ACh and offers capable therapeutic effects [60]. The level of AChE decreases to $90 \%$ in AD patients, causing the loss of function of AChEIs [61]. Whereas BuChE continues the standard level or are upregulated for the metabolism of ACh. Suppression of $\mathrm{BuChE}$ forms a favorable target for drug discovery of progressed AD [62]. So, clinical use of inhibitors of both $\mathrm{AChE}$ and BuChE can be applied for a powerful 
therapeutic strategy for AD. But, presently ChEs suppressors in clinical use, such as donepezil and rivastigmine, only allow a comforting treatment [63]. Therefore, designing multi-target-directed ligands (MTDLs) that can instantaneously control multiple targets in the advancement of $\mathrm{AD}$, has developed as a novel strategy [64] [65] [66], and several of MTDLs have shown favorable pharmacological impacts on AD [67] [68] [69] [70] [71]. A novel series of sixteen multifunctional N-benzyl-piperidine-aryl-acylhydrazones hybrid derivatives were assessed for multi-target activities associated with $\mathrm{AD}$ by Dias et al. [72]. Among them, one compounds showed excellent AChEI activity, also had anti-inflammatory activity in vitro and in vivo, against amyloid beta oligomer $(\mathrm{A} \beta \mathrm{O})$ induced neuroinflammation. The target compound also exhibited the best in vitro and in vivo neuroprotective activity against $\mathrm{A} \beta \mathrm{O}$-induced neurodegeneration. Furthermore, the target compound also revealed a similar binding mode to donepezil in both acetylated and free forms of AChE enzyme in molecular docking studies and did not express toxic effects on in vitro and in vivo assays. Hence, all these consequences authenticated the target compound to be a potent and novel multi-target drug candidate for AD treatment. Furthermore, novel TDMQ (TetraDentate MonoQuinolines) ligands based on an 8-aminoquinolinewere designed [73]. Their affinity for $\mathrm{Cu}$ (II) has been reported, and their competency to suppress oxidative stress encouraged by copper-amyloids initiated by a reductant. These metal ligands can be assessed as potent anti-AD agents; can monitor the homeostasis of copper in brains.

\subsection{Targeting $\beta$-Amyloid: Attractive Therapeutics for AD}

Deposits of insoluble proteins: $\beta$-amyloid (A $\beta)$ and hyperphosphorylated tau are regarded as the primary cause of $\mathrm{AD}$. $\mathrm{A} \beta$ is the product of enzymatic cleavage of amyloid precursor protein (APP) by $\beta$-secretase (BACE-1) and $\gamma$-secretase (Figure 3). Various forms of $\mathrm{A} \beta$, primarily $\mathrm{A} \beta 1-42$ and $\mathrm{A} \beta 1-40$, have the ability to aggregate and create extracellular neurotoxic senile plaques [74]. Amyloid precursor protein (APP) undergoes sequential cleavages by $\beta$-secretase and $\gamma$-secretase and gives rise to the $\beta$-amyloid (A $\beta$ ) that is known to instigate soluble oligomers, insoluble fibrils, and assembled plagues. APP can be processed by $\alpha$-secretase within the $\mathrm{A} \beta$ region and produce a longer $\mathrm{C}$-terminal fragmenting the first cleavage. For controlling $\mathrm{A} \beta$ production, the three important enzymes processing in APP have been therapeutic targets in AD drug development. The strategy is the inhibition of $\beta$ - $\gamma$-secretase while stimulating the $\alpha$-secretase activity. Beta-site APP-cleaving enzyme 1 (BACE1) is the protease in charge for the preliminary cleavage of APP, giving rise to neurotoxic suspect $A \beta$ [75] [76] [77]. BACE1 knock-out mice marked a close correlation between the BACE1 inhibition and the $A \beta$ decline [77] [78]. It is outlined that BACE1 inhibition enhanced memory deficits [79] and released $A \beta$-driven cholinergic dysfunction [80] in APP transgenic mice. Nuclear peroxisome proliferator activated receptor gamma $(\operatorname{PPAR} \gamma)$ act as a transcription factor regulating gene expression [81], 


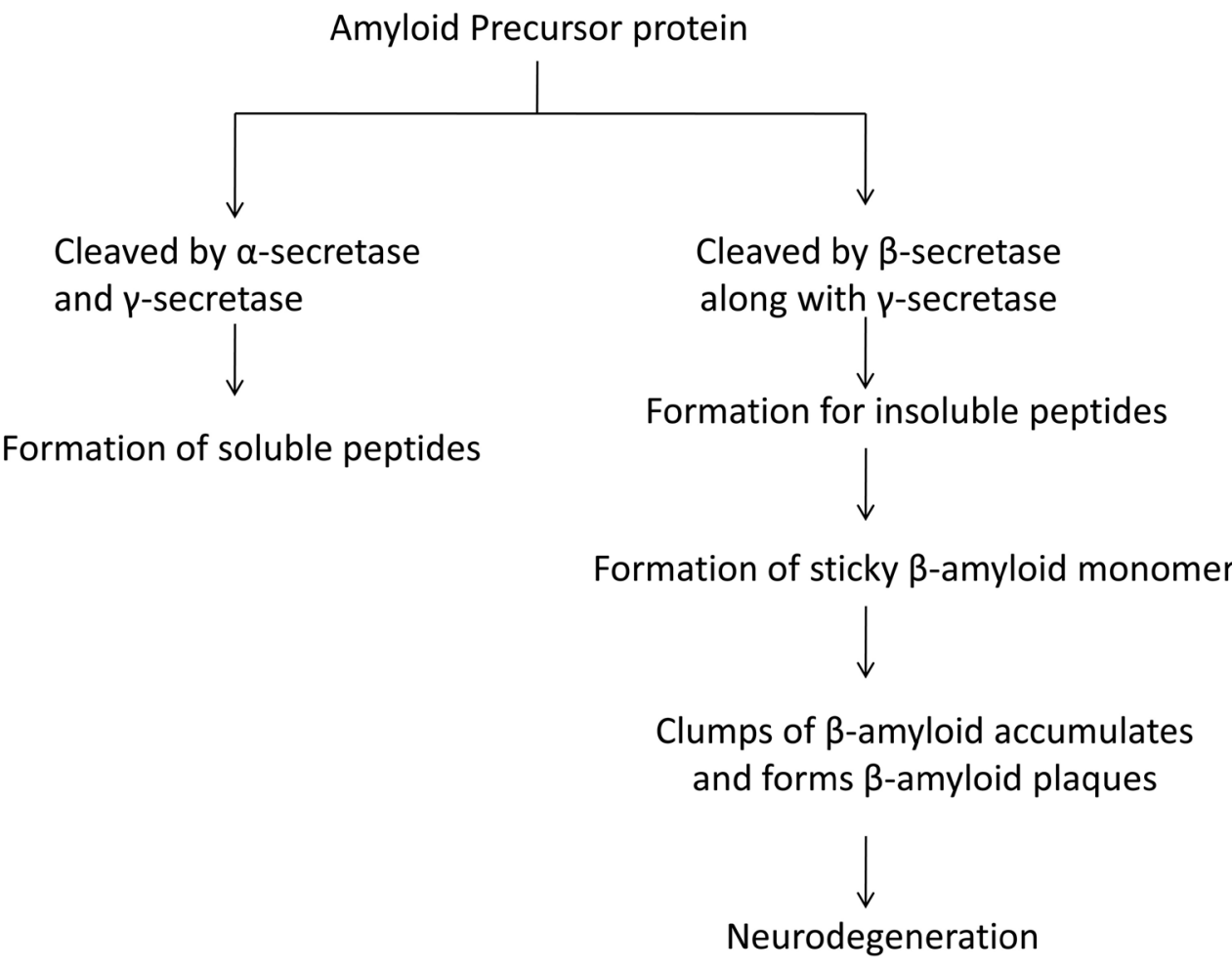

Figure 3. $\beta$-amyloid pathology.

regulating inflammation response, encouraging microglia-mediated $\mathrm{A} \beta$ endocytosis, and decrease cytokine secretion [82]. It was noticed that thiazolidinediones stimulated $\operatorname{PPAR} \gamma$ to inhibit $\beta$-secretase and promoted ubiquitination to deteriorate amyloid load [83]. PPAR $\gamma$ agonists like thiazolidinediones derivatives rosiglitazone and pioglitazone lessen the peripheral insulin resistance [84], which provoked $\mathrm{AD}$ neuropathology, and this decline of insulin sensitivity aids in $\mathrm{A} \beta$ proteolysis. The study of rosiglitazone has been enhanced to a large phase; still, it has been terminated due to cardiac risk concerns [85]. Pioglitazone has recently been developed into a phase 3 clinical trials after preventing an earlier reported bladder risk. Development of small nonpeptidic BACE1 inhibitors, compared to older agents, have enhanced molecular weight, beneficial pharmacokinetic (PK) guidelines, and adequate lipophilicity to cross the blood-brain barrier (BBB) [86] [87]. Lately, orally bioavailable BACE1 inhibitors have been evolved that can cross the $\mathrm{BBB}$ and have shown strong cerebral $\mathrm{A} \beta$ reduction in preclinical animal models [86]. Many of these compounds have been explored in clinical trials [86] [87] [88] [89]. Anti-inflammatory properties of donepezil were studied and its neuroinflammatory effects were also explored [90] [91] [92] [93]. It was observed that donepezil notably reduced the release of inflammatory intermediaries (prostaglandin E2, tumor necrosis factor-a, interleukin-1 beta, and nitric oxide) from microglia. It was further established that donepezil inhibits activated microglia-mediated toxicity in primary hippocampal cells. In intrahippocampal Af30-injected mice, donepezil inhibited microgliosis and astrogliosis. Moreover, behavioral tests showed that donepezil remarkably improved 
$\mathrm{A} \beta 0$-induced cognitive impairment. Thus, it was concluded that donepezil straight away prevents microglial activation induced by $\mathrm{A} \beta$ via obstructing MAPK and NF-KB signaling. This further, brings about the amelioration of neurodegeneration and cognitive impairment. The dosage and duration of treatment of Memogain, another drug, was screened on behavior and amyloid- $\beta(\mathrm{A} \beta)$ plaque deposition in the brain of $\mathrm{AD}$ patients [94]. Their experiments revealed that nasal administration of Memogain efficiently transported the drug to the brain with the possibility to inhibit deposition of plaque and enhance behavioral symptoms in $\mathrm{AD}$. Another novel sequence of flavonoid based compound was designed and produced which showed AChEI activity along with advanced glycation end products (AGEs) inhibitory properties and antioxidant potential as well [95]. One compound 6-methyluracil derivative was found capable of passing through the blood-brain barrier, enhanced working memory in transgenic mice with amyloid precursor protein/PS1 and considerably decreased the $\mathrm{A} \beta$ plaques number and area in the brain [96]. Another compound, $\beta$-asarone notably enhanced the learning and memory of APP/PS1 transgenic mice by suppressing Beclin-1-dependent autophagy via the PI3K/Akt/mTOR pathway [97]. Besides, there was decline in $\mathrm{AChE}$ and $\mathrm{A} \beta_{42}$ levels, improved $\mathrm{p}$-mTOR and $\mathrm{p} 62$ expression, reduced p-Akt, Beclin-1, and LC3B expression, reduced the number of autophagosomes and decline in levels of APP mRNA and Beclin-1 mRNA after treatment with $\beta$-asarone. A natural extract from black sesame (Sesamum indicum L.) known as black sesame pigment (BSP) shows strong inhibition of AChE-induced accumulation of $\beta$-amyloid $A \beta 1-40$ and inhibition of self-induced A $\beta 1-42$ aggregation and activity of BACE-1 [98].

The cellular mechanism of Bis (propyl)-cognitin (B3C) and bis (heptyl)-cognitin effect on the impairments of cognitive function, synapse formation, and synaptic plasticity induced by soluble amyloid- $\beta$ protein $(\mathrm{A} \beta)$ oligomers in $\mathrm{AD}$ patients has been unraveled [99] [100]. A $\beta \mathrm{O}$-induced synaptotoxicity was inhibited by Bis (heptyl)-cognitin in primary hippocampal neurons. Further, it was identified that bis (heptyl)-cognitin changed $A \beta$ assembly via directly preventing $A \beta O$ formation and decreasing the amount of preformed $A \beta O$ 's. Previous research has proved $\mathrm{B} 3 \mathrm{C}$ to be a capable therapeutic anti-AD drug. The effect of a compound, named baicalein on synaptic function both in vitro and in vivo in $\mathrm{AD}$ model was found that baicalein prohibited $\mathrm{A} \beta$-induced impairments in hippocampal LTP via initiation of serine threonine Kinase (Akt) phosphorylation. These findings fortified the flavonoid baicalein effect as potent bioactive therapeutics that avoids memory deficit in AD patients [101]. This compound was also found to enhance scopolamine induced memory deficit in mice. An interesting fact about folic acid is that it prohibited the $\mathrm{A} \beta$ deposition due to folate deficiency in APP/PS1 mice. Folic acid decreased the accumulation of A $\beta 42$ in APP/PS1 mice brain by reducing the mRNA and protein expressions of $\beta$-secretase BACE1 and $\gamma$-secretase complex catalytic component-presenilin 1 (PS1)-in APP/PS1 mice brain [102]. A compound $\alpha 7$ nicotinic acetylcholine receptor ( $\alpha 7-\mathrm{nAChR})$ was 
studied for its binding, $\mathrm{A} \beta$ deposition, and mitochondrial complex I (MC-I) effect in the aged monkeys (Macaca mulatta) brain [103]. The results showed significant upregulation of $\alpha 7$-nAChR caused by neurodegeneration by $\mathrm{A} \beta$ accumulation as well as disabled MC-I activity in brain. Later, Nakaizumi et al. unraveled the association between $\alpha 7-n A C h R$ presence in the specific cholinergic region and cognitive decline in the $\mathrm{AD}$ patients [104]. Relation among $\mathrm{A} \beta$ burden and $\alpha 7-n A C h R$ decrease in the basal forebrain cholinergic system was underlined in accordance to AD cognitive decline. Furthermore, a series of 15 drug-like derivatives of 2-(benzylamino-2-hydroxyalkyl) isoindoline-1,3-diones were identified with $\beta$-secretase inhibitory activities [105]. Another compound, (2-(5-(benzyl amino)-4-hydroxypentyl) isoindoline-1, 3-dione), presented inhibitory potency against eeAChE, $h \mathrm{BACE}-1$, and $\mathrm{A} \beta$-aggregation. Kallikrein-related peptidase 7 (KLK7) was explored as an astrocyte derived degrading enzyme [106]. There was reduced expression of KLK7 mRNA in the of AD patient's brain. It was found that the FDA approved anti-dementia drug memantine elevated the Klk7 expression and degradation of $\beta$ amyloid precisely in the astrocytes. Thus, KLK7 is a significant target enzyme in the deposited $\beta$ amyloid degradation and clearance in $\mathrm{AD}$ patients. Some spiropyrrolidine heterocyclic hybrids in 1-butyl-3-methylimidazoliumbromide ([bmim] $\mathrm{Br}$ ) were identified and reported as promising agents for treating $\mathrm{AD}$ [107]. Pitt et al. speculated CNS factors in physiologically defending neurons from the deleterious effect of $\mathrm{A} \beta \mathrm{O}$ s [108]. Neurons in the presence of astrocytes exhibited decreased $\mathrm{A} \beta \mathrm{O}$ binding and synaptopathy. Insulin and insulin-like growth factor-1 (IGF1) were identified as the defensive factors released by astrocytes. The shielding mechanism involved liberation of newly bound $\mathrm{A} \beta \mathrm{O}$ s into the extracellular medium dependent on trafficking that was delicate to exosome pathway inhibitors. Transmembrane Post-synaptic density (PSD) proteins were scrutinized heterologously for the capability to bind $\mathrm{A} \beta \mathrm{O}-\mathrm{PrP}(\mathrm{C})$ with Fyn [109]. Coexpression of the metabotropic glutamate receptor, $\mathrm{mGluR5}$, permitted $\operatorname{PrP}(\mathrm{C})$-bound $\mathrm{A} \beta \mathrm{O}$ to activate Fyn. $\operatorname{PrP}(\mathrm{C})$ and mGluR5 communicate physically, and cytoplasmic Fyn establishes a complex with mGluR5. A $\beta \mathrm{O}-\operatorname{PrP}(\mathrm{C})$ multiplexes at the neuronal surface activate mGluR5 to damage neuronal function. Further, Haas group reported that the $\operatorname{Pr} \mathrm{P}(\mathrm{C})$ segment of amino acids 91 - 153 facilitates the interaction with mGluR5 [110]. mGluR5 agonists intensify the mGluR5-PrP(C) interaction, whilemGluR5 antagonists inhibit protein association. In brain homogenates with $\mathrm{A} \beta \mathrm{O}$, the interaction of $\operatorname{Pr} \mathrm{P}(\mathrm{C})$ and mGluR5 was reversed by mGluR5-directed competitor or antibodies administered against the $\operatorname{PrP}(\mathrm{C})$ segment of amino acids 91-153. It was seen that silent allosteric modulators of mGluR5 did not alter Glu or basal mGluR5 property; instead they disrupted the $\mathrm{A} \beta \mathrm{O}$-induced interaction of mGluR5 with $\operatorname{Pr} P(C)$. The findings described here has the prospective to detect novel compounds that prevent the interaction of $\operatorname{Pr} \mathrm{P}(\mathrm{C})$ and mGluR5, which is very crucial for AD pathogenesis. Stress-inducible phosphoprotein 1 (STI1), an Hsp90 cochaperone released by astrocytes in $\mathrm{A} \beta \mathrm{O}$ toxicity was stu- 
died [111]. The precise binding of A $\beta$ Os and STI1 to the cellular Prion protein $(\operatorname{PrP}(\mathrm{C}))$ was validated and displayed that STI1 capably repressed $\mathrm{A} \beta \mathrm{O}$ binding to $\operatorname{PrP}$ in vitro and reduced $\mathrm{A} \beta \mathrm{O}$ binding to cultured mouse primary hippocampal neurons. Significantly, TPR2A inhibited both $A \beta O$ binding to $\operatorname{PrP}(C)$ and $\operatorname{PrP}(\mathrm{C})$-dependent $\mathrm{A} \beta \mathrm{O}$ toxicity, the $\operatorname{Pr} \mathrm{P}(\mathrm{C})$-interacting domain of STI1. Furthermore, $\operatorname{PrP}(\mathrm{C})$-STI1 stimulated $\alpha 7$ nicotinic acetylcholine receptors, thereby contributing in neuroprotection against $\mathrm{A} \beta \mathrm{O}$-induced toxicity. Furthermore, Maciejewski et al. explored the molecular interactions between $\mathrm{A} \beta \mathrm{O}$ and STIP1 attachment to $\operatorname{Pr} \mathrm{P}(\mathrm{C})$ and their consequences on neuronal cell death [112]. They reported that residues situated in the short region of $\operatorname{PrP}(90$ - 110) facilitate $A \beta O$ binding. PrP binding was caused because of multiple binding sites on STIP1. The TPR2A (one of the binding site on STIP1) interface was found to be very vast and moderately overlayed with the Hsp90 binding site. Thus, there is a likelihood of a PrP, STIP1 and Hsp90 ternary complex, which may impact $\mathrm{A} \beta \mathrm{O}$-mediated cell death.

It is known that proteolysis of APP is vital for $\beta$-amyloid peptides (A $\beta$ ) production which deposits as disorientated plaques in brains of patients with AD. The BACE1 is the rate determining enzyme in the formation of $\mathrm{A} \beta$ from APP. Dai et al. used the inhibition of BACE1 strategy for the development of drug for $\mathrm{AD}$ [113]. Chitosan oligosaccharides (COS) has been known to hold numerous biological activities. The experimental data showed that COS reduced the cell apoptosis, and strongly suppressed the secretion of both $\mathrm{A} \beta 40$ and $\mathrm{A} \beta 42$. Furthermore, COS treatment reduced the BACE1 mRNA and protein expression level, eIF2 $\alpha$ phosphorylation as well as the enzymatic activity of BACE1. They concluded that $\operatorname{COS}$ contained properties that could ameliorate $\mathrm{A} \beta$-associated neurodegeneration, thereby contributing to drops in BACE1 enzymatic activity and expression.

Wang et al. conducted an $\mathrm{AD}$ mice vaccine development experiment where they immunized the mice with AOE1 vaccine comprising mimotope L2 induced antibodies that precisely identified $\mathrm{A} \beta 42$ oligomers and found that it decreased the levels of $\mathrm{A} \beta$ oligomers and activation of glial in the $\mathrm{AD}$ mouse brains [114]. $\mathrm{A} \beta$-specific $\mathrm{T}$ cells were not activated in their brains and no microhemorrhages activation was detected in their brains after AOE1 vaccination. A different approach of disease modification was used by Giannoni et al. to combat AD [115]. They identified a potent 5 -HT4 receptor agonist RS67333 which reduced A $\beta$ production level which led to decline in hippocampal astrogliosis and microgliosis. Jung et al. revealed the neuroprotective effects of Cassiae obtusifolia semen which could be promising therapeutic anti-AD agents as it possessed the inhibitory activity against AChE, BChE and BACEl [116]. Earlier it has been reported that the Cassiae obtusifolia seeds extracts, have memory ameliorating properties and anti-AD activity to enhance amyloid $\beta$-induced synaptic dysfunction [117] [118]. Xu et al. evaluated the function of SNX3 in A $\beta$ production and processing of APP. Their findings suggested that overexpression of SNX3 in 
HEK293T cells reduces the A $\beta$ level and soluble $N$-terminal APP fragments $(\operatorname{sAPP} \beta)$ [119]. SNX3 overexpression decreased APP internalization, and formed increased level of APP on the cell surface. Further, SNX3 overexpression ameliorated the level of APP.

Esmaeili et al. concluded that obstruction of $\mathrm{K}_{\mathrm{ATP}}$ channels with glibenclamide reduced depression- and anxiety-related behaviors by regulating HPA axis activity in A $\beta 25$-35-treated rats [120]. Ge et al. reported that soluble islet amyloid polypeptide (IAPP) encouraged the accumulation of $\mathrm{A} \beta 42$ by binding-induced conformational modification of $\mathrm{A} \beta 42$ in its amyloidogenic core and hence decreased aggregation free energy barrier [121]. Hall group reported the M1/sigma-1 activity and long-lasting disease-modifying properties of a compound AF710B, as a potent anti-AD agent [122]. The cognitive deficits related with progressive Alzheimer-like amyloid neuropathology were reverted in transgenic rats after long term treatment with AF710B. AF710B was reported as capable to induce the binding and efficacy of carbachol on M1 receptors and their downstream effects (phopho-ERK1/2, phospho-CREB) at low concentrations. In accord with its anti-amnesic effect, AF710B, via activation of M1 and a possible involvement of $\sigma 1$ receptors, retrieved mushroom synapse loss in PS1-KI and APP-KI neuronal cultures. There were decrease in amyloid pathology and markers of neuroinflammation and elevation in amyloid cerebrospinal fluid clearance and levels of a synaptic marker. Wang et al. designed and created a series of new 4 -isochromanonecompounds having $N$-benzyl pyridinium moiety and biological assessment displayed that most of the target compounds revealed potent AChEI activities [123]. Fisher et al. reported AF710B, to be an effective and selective allosteric M1 muscarinic and $\sigma 1$ receptor agonist [124]. In female transgenic AD mice AF710B reduced cognitive impairments, also reduced BACE1, GSK3 $\beta$ activity, p25/CDK5, neuroinflammation, soluble and insoluble $\mathrm{A} \beta 40, \mathrm{~A} \beta 42$, plaques and tau pathologies. Clemens et al. validated the co-relation between inflammation, retinoic acid (RA) signaling, and Apolipoprotein E (ApoE) homeostasis in origin and development of AD [125]. Microglia is an important source of ApoE, and is known to be pathologically stimulated in AD. RA signaling is known to be inhibited by these microglia and proinflammatory stimulation reduces synthesis of ApoE, due to an effect blocked by RA. Sans et al. demonstrated the cellular model for evaluating apoE proteolysis, which showed that serine peptidase A1 (HtrA1) controlled apoE 25-kDa fragment production under physiological conditions, and depicts a novel neurotrophic effect for the apoE fragment [126]. Studies on CSF have shown that levels of CSF of amyloid-beta 1-42 (A $\beta 42)$ are decreased and tau levels ameliorated earlier to the commencement of cognitive decline related to AD. Leon et al. noticed that the prognosis of cognitive decline was enhanced by taking into account both high and low levels of $\mathrm{A} \beta 42$ [127]. Their data proposed a preliminary preclinical stage, manifested by CSF increase in tau and escorted by elevations or diminution in $\mathrm{A} \beta 42$. Chen et al. designed and analyzed a series of tacrine-cinnamic acid 
hybrids as novel ChEIs [128]. All target compounds are assessed for their in vitro ChEI activities. Those compounds which revealed effective ChEI activity were further screened for the $\mathrm{A} \beta$-protein self-accumulation inhibition and in vivo assays. Three compounds were found to be helpful in enhancing the scopolamine-induced cognition impairment and preliminary safety in hepatotoxicity assessment and claimed as potential novel therapeutic anti-AD agents.

Several findings have shown that monoamine oxidase (MAO) plays a vital role in the pathogenesis of $\mathrm{AD}$ because the elevation of MAO in the brain may produce a cascade of biochemical events resulting in neuronal dysfunction [129] [130]. MAOs are flavin adenine dinucleotide (FAD)-containing enzymes that are accountable for the oxidative deamination of endogenous and exogenous monoamine substances. There are two functional isozymic forms of MAOs, mainly, MAO-A and MAO-B [131]. MAO-A inhibitors are applied in clinical antidepressants and antianxiety, while MAO-B inhibitors are used as a remedy for neurodegenerative disorders such as $\mathrm{AD}$ and Parkinson's diseases (PD) [132] [133]. Based on previous research [134] [135], MAO-B action in the brain and blood platelets of $\mathrm{AD}$ patients were high, while increased expression levels of MAO-B could result in the enhanced level of free radicals that portrayed a significant role in $\mathrm{AD}$ pathogenesis. MAO-B inhibitors can decrease the oxidative stress response and guard the nerve cells from oxidative damage and neurotoxicity, hence, MAO-B could be a significant target for AD treatment [136] [137]. Selegiline, an irreversible and selective MAO-B inhibitor, has been described as a potent anti-AD agent because of its neuroprotective attribute in cellular and animal models of $\mathrm{AD}$ [138]. The elevated levels and dysregulation of biometal ions such as $\mathrm{Cu}^{2+}, \mathrm{Zn}^{2+}$ and $\mathrm{Fe}^{2+}$ were found to be closely involved in $\mathrm{AD}$ pathogenesis [139] and was reported to promote $\mathrm{A} \beta$ aggregation, resulting in the production of toxic $\mathrm{A} \beta$ oligomers [140]. Redox-active $\mathrm{Cu}$ (I/ II) and Fe (II/III) are involved in the creation of reactive oxygen species (ROS) causing an increase in oxidative stress [141] [142] [143] [144]. Biometal chelators, particularlyCu ${ }^{2+}$ chelators, decrease the metal-induced $\mathrm{A} \beta$ aggregation and also minimize the ROS level generated by the redox metal and metal- $\mathrm{A} \beta$ complex [145] [146]. Hence, biometal chelators have been believed to be a potent therapeutic strategy for $\mathrm{AD}$ treatment. Moreover, neurotoxic ROS and oxidative damage of neuronal cells are also related to $\mathrm{AD}$, so the compounds with antioxidant properties could be favorable for $\mathrm{AD}$ treatment [147] [148]. Vilella et al. screened altered zinc-levels in the $\mathrm{AD}$ brain via zinc loaded nanoparticles which can deliver zinc into the brain across the $\mathrm{BBB}$ for favorable effect on $\mathrm{AD}$ patients [149]. In vivo studies were conducted with wild type (WT) and APP23 mice to evaluate plaque load, inflammatory status and synapse damage. Besides, behavioral analyses were undertaken. A remarkable decrease in plaque size and impact on the pro-inflammatory cytokines 11-6 and IL-18 was seen after administering these nanoparticles for 14 days. In case of behavioral changes there was no negative result of increased brain zinc levels in APP23 mice and treatment with g7-NP-Zn 
standardized the detected hyperlocomotion of APP23 mice.

Mitochondria association has been revealed in the disease pathogenesis of AD [150]. The member of quinone family is key mitochondrial targets used as the curative against ROS-mediated impairment. To avoid oxidative injury in AD, Mitoquinone mesylate or MitoQ, a ubiquinone derivative has been applied [151]. Zhang et al. discovered novel Phosphodiesterase-9 (PDE9) inhibitors [152]. This PDE9is a promising target for AD treatment. AD is marked by continuous cognitive decline, progressively associated with neuronal dysfunction caused by amyloid- $\beta$ oligomers (A $\beta \mathrm{O}$ ). Diniz et al. reported that $\mathrm{A} \beta \mathrm{O}$ s interact with astrocytes, triggers astrocyte activation and causes abnormal production of reactive oxygen species (ROS), which is accompanied by damage of astrocyte neuroprotective potential in vitro [153]. They demonstrated that astrocyte stops the synapse damage induced by $\mathrm{A} \beta \mathrm{Os}$, through formation of transforming growth factor- $\beta 1$ (TGF- $\beta 1$ ). A $\beta$ Os also causes morphological and functional modifications in astrocytes, and weaken their neuroprotective potential. These findings outline a new strategy unrevealed the toxicity of $\mathrm{A} \beta \mathrm{O}$ s and specify a novel therapeutic target for $\mathrm{AD}$, primarily focused on TGF- $\beta 1$ and astrocytes.

$\mathrm{Yu}$ et al. earlier reported that the inhibition of histone deacetylase 3 (HDAC3) enhances spatial memory deficits and reduces the $\mathrm{A} \beta$ accumulation in the 9-month-old APP/PS1 mice brain [154]. Recently, they opened new frontiers for $\mathrm{AD}$ drug development by proposing HDAC3 to be a promising target because of their effect of reducing spatial memory deficits and preventing oxidative stress in APP/PS1 mice. HDAC3 is mainly present in the neurons; its inhibition notably attenuates production of ROS and enhanced primary cortical neuron viability. Researchers determined a molecular association between aging and dementia via the identification of J147 a molecular target for the AD drug [155]. Mitochondrial a-F1-ATP synthase (ATP5A) was identified as a target fora potential drug candidate J147.It was found that J147 ameliorated intracellular calcium level which induced calcium/calmodulin-dependent protein kinase kinase $b$ (CAMKK2)-dependent activation of the AMPK/mTOR pathway, an established longevity procedure. Hence, ATP synthase prove to be a potential target which could be further explored for $\mathrm{AD}$ drug development. Xu et al. synthesized new propargyl amine-modified pyrimidinylthiourea derivatives (1e3) for AD treatment, and evaluated their potential through numerous biological experiments [156]. These derivatives showed good selective inhibitory activity against acetylcholinesterase (AChE) and monoamine oxidase (MAO-B). Molecular studies displayed that the pyrimidinylthiourea moiety of $1 \mathrm{~b}$ possibly bind to the catalytic active site (CAS) of $\mathrm{AChE}$, and the propargylamine moiety cooperated directly with the flavin adenine dinucleotide (FAD) of MAO-B. Furthermore, $1 \mathrm{~b}$ confirmed significant antioxidant capability, good copper chelating property, effective inhibitory activity against $\mathrm{Cu} 2 \mathrm{p}$-induced $\mathrm{A} \beta 1$-42aggregation, moderate neuroprotection, little cytotoxicity, and suitable blood brain barrier permeability 
in vitro and was found to be able of ameliorating scopolamine-induced cognitive impairment in mice. Their findings showed that $1 \mathrm{~b}$ has the possible potential to act as a multifunctional candidate for the treatment of $\mathrm{AD}$. Monoamine oxidase inhibitors (MAOIs) are potential drug candidates for the treatment of various neurological disorders like Parkinson's disease, $\mathrm{AD}$ and depression. Kumar et al. evaluated MAO-A and MAO-B inhibitory activities of two series of 4-substituted phenylpiperazine and 1-benzhydrylpiperazine derivatives, and found them to be strong MAO inhibitors [157]. Birnbaum et al. reported that improved production of ROS may have an integral role in the advancement of sporadic AD prior to the emergence of amyloid and tau pathology [158].

\subsection{Targets and Small Molecules against Tauopathies}

Tau accumulation association with neurodegeneration in $\mathrm{AD}$ and associated tau-positive neurological disorders collectively known as tauopathies directs the involvement of tau aggregates to neurotoxicity (Figure 4). Delrieu et al. aimed at developing a new third phase 3 clinical trials for solanezumab, called expedition 3 , in patients with minor $\mathrm{AD}$ and sign of amyloid accumulation has been started. Previously designed drug solanezumab seems to be more successful when used in early stages of amyloid accumulation, showing the importance of detecting $\mathrm{AD}$ as early as possible and undergoing clinical trials at this stage [159]. Gibbons et al. identified novel tau monoclonal antibodies (mAbs) that allowed the selective recognition of $\mathrm{AD}$ tau pathology by selectively binding to an $\mathrm{AD}$-specific tau conformation [160].

Lo et al. developed Azure C (AC), which is competent of regulating tau oligomer accumulation pathways at minimal concentrations and releases tau oligomers-induced toxicity in cell culture [161]. Remarkably, AC inhibited toxicity by transforming the oligomers into groups of aggregates with non-toxic conformation.

\section{Normal Tau proteins \\ in Healthy} Microtubules

\section{B-Amyloid activates kinase}

Conformational changes occurs in Tau Proteins<smiles>C=[13CH]</smiles>

Clumps up with other tau proteins and forms Tangles

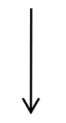

Leads to cell death/Apoptosis

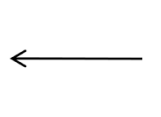

Unhealthy Microtubules
Formation of Neurofibrillary Tangles occurs

Figure 4. Tau pathology. 
Tiernan et al. revealed the spatiotemporal progression of oligomeric tau accumulation within the highly vulnerable cholinergic neurons of the nucleus basalis of Meynert (nbM) in AD [162]. They concluded that toxic tau oligomers multiply in selectively susceptible nbM neurons through the progression of $\mathrm{AD}$. Yang et al. designed the reagent for assessing plasma phosphorylated tau protein (p-tau181) with immunomagnetic reduction (IMR) and classified its analytic performances [163]. Their findings revealed that the level of plasma $\mathrm{p}$-tau181 is associated more to $\mathrm{AD}$ severity than plasma $\mathrm{T}$-tau.

\subsection{Other Strategies}

The anti-AD activities of different parts of Nelumbo nucifera (leaves, de-embryo seeds, embryos, rhizomes, and stamens) were explored to assess the selectivity and resourceful usage of its specific components [164]. It was noticed that the embryo extract act as a potent suppressor of BACEl and BChE and also has scavenging activity against $\mathrm{ONOO}^{-}$. Further evaluation showed that dichloromethane $\left(\mathrm{CH}_{2} \mathrm{Cl}_{2}\right)$, ethyl acetate (EtOAc), and n-butanol (n-BuOH) fractions showed promising ChEI and BACEl inhibitory activities. Similar activities were shown by compounds obtained from Corni Fructus: loganin, morroniside, and 7-0-galloyl-o-sedoheptulose [165], these compounds had triple inhibitor activity for AChE, BChE, and BACE1 suggesting it to be a potent therapeutic class of agents for $\mathrm{AD}$ treatment. Further, the anti-AD activities of ginsenosides (Rbt, $\mathrm{Rb} 2$, Re, Re, Rg1, and Rg3) conferring to $\mathrm{ONOO}^{-}$scavenging activity and suppressor activity of ONOO mediated nitrotyrosine formation was reported [166]. Various in vitro enzyme assays established that ginsenosides possess substantial inhibitory activity against $\mathrm{AChE}, \mathrm{BChE}$, and $\mathrm{BACE} 1$ as well as $\mathrm{ONOO}^{-}$and nitrotyrosine formation. Inula japonica, a member of the Asteraceae plant family and its flowers has been used as a healthy tea and a traditional Chinese medicine. Liu et al. reported two new sesquiterpenes and ten known terpenes from the flowers of I. japonica [167]. Their findings revealed the flowers of I. japonica to be a healthy tea and potentially helpful for $\mathrm{AD}$ and related neuroinflammatory diseases. Baicalin is known to possess anti-inflammatory and neuroprotective properties. Chen et al. studied the neuroprotective influence of baicalin and found that baicalin enhanced $\mathrm{A} \beta$ (1-42) protein-related pathology and cognitive dysfunction through its anti-neuroinflammatory property [168].

Astrocytes have shown to play a vital role in CNS homeostasis and neuronal function maintenance. $\mathrm{Tg}$ astrocytes presented many prominent effects such as basal inflammatory status, with heightened reactivity and improved expression of the inflammatory cytokine interleukin-1 beta (IL-1 $\beta$ ), the hexose monophosphate shunt was stimulated, also the initiation of hypoxia inducible factor-1 alpha (HIF-1 $\alpha$ ), which aids in insulation against $\mathrm{A} \beta$ toxicity [169]. Furthermore, Pantethine, the vitamin B5 precursor, has a neuroprotective and anti-inflammatory effect, improved the pathological pattern in Tg astrocytes as well as WT astrocytes treated with $\mathrm{A} \beta$. Their findings showed the dual defensive role of astrocytes 
in $\mathrm{AD}$ and the shielding effect of pantethine. The dietary vitamin $\mathrm{D}$ addition in female AD-like mice decreased cognitive decline only when applied in the symptomatic phase [170]. It was proposed that transcranial ultrasound can securely and efficiently modify the brain interstitium and enhance the diffusion of large therapeutic drug carriers, which has a promising potential to develop the therapeutic uses of MRgFUS [171]. Neurons with hyperphosphorylated tau in $\mathrm{AD}$ has the profile of metabolically active cells including amplified exportin-5 and importin- $\beta$ mRNA and proteins which signifies that immunohistochemistry evaluation of these proteins may assist in the early diagnosis of $\mathrm{AD}$ [172].

Compounds comprising a benzofuran ring have been defined to have a vital role in reducing $\mathrm{A} \beta$-induced toxicity, though, till date only synthetic benzofurans have been inspected. González et al. explored in vitro neuroprotective properties of fomannoxin ( $\mathrm{Fx}$ ), a natural benzofuran isolated from the Andean-Patagonian fungi Aleurodiscus vitellinus cultures, and noted its neuroprotective effect against $\mathrm{A} \beta$ peptide toxicity [173]. Paley et al. previously proposed that tryptophan metabolites lead to neurotoxicity and neurodegeneration in $\mathrm{AD}$ patients [174]. Tryptophan is known to be a product of Shikimate pathway (SP). There is no SP in human cells, instead human gut bacteria use SP to yield aromatic amino acids (AAA). Recently, gene-targeted investigation of human gut microbiota in AD fecal samples was carried out by this group of scientists. The remarkable variance in the gut microbial genotypes between the $\mathrm{AD}$ and control human populations was a significant achievement. Research was carried out on the function and role of pro-opio melanocortin (POMC)-derived neuropeptides and melanocortin 4 receptor (MC4R) in hippocampus-dependent synaptic plasticity, whose damage leads to cognitive deficits in $\mathrm{AD}$ [175]. It was seen that proinflammatory peripheral blood mononuclear cell (PBMC)-derived cytokines level was ameliorated in $\mathrm{AD}$ patients as compared with healthy controls and donepezil treatment minimized proinflammatory cytokines [176]. Atorvastatin treatment notably enhanced cognitive deficits of rats, diminished microglia and activation of astrocyte, prevented apoptosis, and down-regulated the expression of TLR4, TRAF6, and NF- $\mathrm{BB}$, at the mRNA and protein levels as well [177]. TLR4 signaling pathway is therefore vigorously involved in $A \beta$-induced neuroinflammation and treatment with atorvastatin can exert therapeutic effects for AD. A nonselective $\beta$-adrenergic receptor blocker, Carvedilol, applied in the treatment for heart failure and hypertension, and has exhibited neuroprotective property due to its antioxidant attribute. Liu and Wang reported that Carvedilol restrained apoptosis signals by decreasing cytochrome $\mathrm{C}$ release and cleaved caspase-3 level [178]. Thus, favourable use of Carvedilol in $\mathrm{AD}$ treatment can be further explored. Simvastatin is known to be a cholesterol-lowering statin drug that has been employed to control blood cholesterol level, mainly in cases of hypercholesterolemia. Hu et al. proposed that Simvastatin may be helpful in enhancing the clinical consequences of $\mathrm{AD}$ patients [179]. Batista et al. identified means of neuroprotection by liraglutide, and suggested that glucagon-like pep- 
tide-1 (GLP-1) receptor activation may be utilized to defend receptors of brain insulin and synapses in AD [180].

The role of erythropoietin-producing hepatocellular A4 (EphA4) in mediating hippocampal synaptic dysfunctions in $\mathrm{AD}$ was explored and it was seen that synaptic impairment is altered by the blockade of the ligand-binding domain of EphA4 in AD mouse models [181]. Their studies disclosed an anonymous role of EphA4 in facilitating AD-associated synaptic dysfunctions, indicating it to be a novel therapeutic target for treatment of $\mathrm{AD}$.

\section{Conclusions}

$\mathrm{AD}$ attributes a vigorous progression of $\beta$-amyloid accumulation, neurodegeneration, and cognitive impairment. It is the most widespread age-related neurodegenerative disturbance influencing millions of people worldwide. Thus, discovery of an effective intervention and therapies is extremely important. Medications are immediately needed for the treatment of $\mathrm{AD}$ and unfortunately nearly entire clinical trials of $\mathrm{AD}$ drug candidates in the past have failed or have been obsolete to date. A number of available tools such as mathematical, computational or statistical tools can be employed for the clinical trial simulators development for the advancement of trial design and thus aid in the success of possible novel therapies. Drugs aimed at more than one target could reduce an excessive impact in the intricate nerve network, this combination procedure known as multi target-directed ligands (MTDLs) might lead to the discovery of novel therapeutics for AD [182] [183]. Previously designed multitarget compounds include, dual binding AChE and BACE1 inhibitors [184], AChE inhibitors and antioxidants [185]. Presently, multiple-pharmacology natural products can be employed in the drugs designing of AD treatment [186], Herbal formulae like Kai-Xin-San (consisting of Ginseng Radix, Poria, Polygalae Radix, and Acori Tatarinowii Rhizoma) also found to be effective in the treatment of AD [187] [188]. Novel strategies, such as quantitative systems pharmacology [189], chemogenomics knowledgebase [190], metabolomics [191]-[196] and chinmedomics [197]-[202] can be further explored for the finding of new generation drugs for AD. Several reviews on different strategies employed for potential target have been reported [1] [203] [204] [205] [206]. The impact of understanding Alzheimer pathogenesis can aid in developing novel therapeutic strategies with the objective of moving from treatment to prevention.

$\mathrm{AD}$, the commonest dementia, is a rising worldwide health concern in today's world with immense implications for patients and societies as well. In this review, we have demarcated the current knowledge of the epidemiology, genetics, pathology and pathogenesis of $\mathrm{AD}$, which is a prerequisite for the successful development of an effective therapy for the treatment of $\mathrm{AD}$. Because the deposition of $\beta$-amyloid protein is a consistent pathological hallmark of brains affected by $\mathrm{AD}$, the inhibition of Amyloid- $\beta$ generation, prevention of Amyloid- $\beta$ fibril formation, destabilization of pre-formed Amyloid- $\beta$ would be an attractive the- 
rapeutic strategy for the treatment of AD. Finally, the review discusses the various strategies which can be applied for an effective treatment for AD. Given the diverse strategies employed to develop potent therapeutic approach, there is hope that a viable drug targeting key components will be developed in our fight against $\mathrm{AD}$ in the not too distant future.

\section{Acknowledgements}

The authors express appreciation for Grants supported by the National Center for Research Resources and the National Institute of General Medical Sciences of the National Institute of Health through Grant number 8P20 GM 103475, and in kind support time and efforts from Universidad Metropolitana for research.

\section{Conflicts of Interest}

The authors declare no conflict of interest, financially or otherwise.

\section{References}

[1] Lane, C.A., Hardy, J. and Schott, J.M. (2018) Alzheimer's Disease. European Journal Neuroscience, 25, 59-70. https://doi.org/10.1111/ene.13439

[2] Rizzi, L., Rosset, I. and Roriz-Cruz, M. (2014) Global Epidemiology of Dementia: Alzheimer's and Vascular Types. BioMed Research International, 2014, Article ID 908915. https://doi.org/10.1155/2014/908915

[3] Imbimbo, B.P., Lombard, J. and Pomara, N. (2005) Pathophysiology of Alzheimer's Disease. Neuroimaging Clinics of North America, 15, 727-753. https://doi.org/10.1016/j.nic.2005.09.009

[4] Alzheimer's Association (2013) Alzheimer's Disease Facts and Figures. Alzheimer's Dementia, 9, 208-245. https://doi.org/10.1016/j.jalz.2013.02.003

[5] Goedert, M. and Spillantini, M.G. (2006) A Century of Alzheimer's Disease. Science, 314, 777-781. https://doi.org/10.1126/science.1132814

[6] Talesa, V.N. (2001) Acetylcholinesterase in Alzheimer's Disease. Mechanism of Ageing and Development, 122, 1961-1969.

https://doi.org/10.1016/S0047-6374(01)00309-8

[7] Hardy, J. and Selkoe, D.J. (2002) The Amyloid Hypothesis of Alzheimer's Disease: Progress and Problems on the Road to Therapeutics. Science, 297, 353-356. https://doi.org/10.1126/science.1072994

[8] Hardy, J. (2006) Alzheimer's Disease: The Amyloid Cascade Hypothesis: An Update and Reappraisal. Journal of Alzheimer's Disease, 9, 151-153. https://doi.org/10.3233/JAD-2006-9S317

[9] Barnham, K.J., Masters, C.L. and Bush, A.I. (2004) Neurodegenerative Diseases and Oxidative Stress. Nature Reviews Drug Discovery, 3, 205-214. https://doi.org/10.1038/nrd1330

[10] Hegde, M.L., Bharathi, P., Suram, A., Venugopal, C., Jagannathan, R., Poddar, P., Srinivas, P., Sambamurti, K., Rao, K.J., Scancar, J., Messori, L., Zecca, L. and Zatta, P. (2009) Challenges Associated with Metal Chelation Therapy in Alzheimer's Disease. Journal of Alzheimer's Disease, 17, 457-468. https://doi.org/10.3233/JAD-2009-1068

[11] Bolognin, S., Drago, D., Messori, L. and Zatta, P. (2009) Chelation Therapy for 
Neurodegenerative Diseases. Medicinal Research Reviews, 29, 547-570. https://doi.org/10.1002/med.20148

[12] Kumar, A., Nisha, C.M., Silakari, C., Sharma, I., Anusha, K., Gupta, N., Nair, P., Tripathi, T. and Kumar, A. (2016) Current and Novel Therapeutic Molecules and Targets in Alzheimer's Disease. Journal of the Formosan Medical Association, 115, 3-10. https://doi.org/10.1016/j.jfma.2015.04.001

[13] Anand, P. and Singh, B. (2013) A Review on Cholinesterase Inhibitors for Alzheimer's Disease. Archives of Pharmacal Research, 36, 375-399. https://doi.org/10.1007/s12272-013-0036-3

[14] Lo, D. and Grossberg, G.T. (2011) Use of Memantine for the Treatment of Dementia. Expert Review of Neurotherapeutics, 11, 1359-1370.

https://doi.org/10.1586/ern.11.132

[15] Stahl, S.M. (2013) Stahl's Essential Psychopharmacology. Neuroscientific Basis and Practical Applications. 4th Edition, Vol. 8, Cambridge University Press, Cambridge, 146-150.

[16] Vassar, R., Kuhn, P.H., Haass, C., Kennedy, M.E., Rajendran, L., Wong, P.C. and Lichtenthaler, S.F. (2014) Function, Therapeutic Potential and Cell Biology of BACE Proteases: Current Status and Future Prospects. Journal of Neurochemistry, 130, 4-28. https://doi.org/10.1111/jnc.12715

[17] Oehlrich, D., Prokopcova, H. and Gijsen, H.J. (2014) The Evolution of Amidine-Based Brain Penetrant BACE1 Inhibitors. Bioorganic and Medicinal Chemistry Letters, 24, 2033-2045. https://doi.org/10.1016/j.bmcl.2014.03.025

[18] Lewerenz, J. and Maher, P. (2015) Chronic Glutamate Toxicity in Neurodegenerative Diseases-What Is the Evidence? Frontiers in Neuroscience, 9, 469-489. https://doi.org/10.3389/fnins.2015.00469

[19] Hu, N.W., Ondrejcak, T. and Rowan, M.J. (2012) Glutamate Receptors in Preclinical Research on Alzheimer's Disease: Update on Recent Advances. Pharmacology Biochemistry and Behavior, 100, 855-862. https://doi.org/10.1016/j.pbb.2011.04.013

[20] Xie, Q., Wang, H., Xia, Z., Lu, M., Zhang, W., Wang, X., Fu, W., Tang, Y., Sheng, W., Li, W., Zhou, W., Zhu, X., Qiu, Z. and Chen, H. (2008) Bis-(-)-Nor-Meptazinols as Novel Nanomolar Cholinesterase Inhibitors with High Inhibitory Potency on Amyloid-Beta Aggregation. Journal of Medicinal Chemistry, 51, 2027-2036. https://doi.org/10.1021/jm070154q

[21] Munoz-Torrero, D. (2008) Acetylcholinesterase Inhibitors as Disease-Modifying Therapies for Alzheimer's Disease. Current Medicinal Chemistry, 15, 2433-2455. https://doi.org/10.2174/092986708785909067

[22] Shao, Z.-Q. (2015) Comparison of the Efficacy of Four Cholinesterase Inhibitors in Combination with Memantine for the Treatment of Alzheimer's Disease. International Journal of Clinical and Experimental Medicine, 8, 2944-2948.

[23] Takeda, A., Loveman, E., Clegg, A., Kirby, J., Picot, J., Payne, E. and Green, C. (2006) A Systematic Review of the Clinical Effectiveness of Donepezil, Rivastigmine and Galantamine on Cognition, Quality of Life and Adverse Events in Alzheimer's Disease. International Journal of Geriatric Psychopharmacology, 21, 17-28. https://doi.org/10.1002/gps.1402

[24] Raina, P., Santaguida, P., Ismaila, A., Patterson, C., Cowan, D., Levine, M., Booker, L. and Oremus, M. (2008) Effectiveness of Cholinesterase Inhibitors and Memantine for Treating Dementia: Evidence Review for a Clinical Practice Guideline. Annals of Internal Medicine, 148, 379-397.

https://doi.org/10.7326/0003-4819-148-5-200803040-00009 
[25] Grossman, I., Lutz, M.W., Crenshaw, D.G., Saunders, A.M., Burns, D.K. and Roses, A.D. (2010) Alzheimer's Disease: Diagnostics, Prognostics and the Road to Prevention. EPMA Journal, 1, 293-303. https://doi.org/10.1007/s13167-010-0024-3

[26] Thal, L.J., Kantarci, K., Reiman, E.M., Klunk, W.E., Weiner, M.W., Zetterberg, H., Galasko, D., Praticò, D., Griffin, S., Schenk, D. and Siemers, E. (2006) The Role of Biomarkers in Clinical Trials for Alzheimer Disease. Alzheimer Disease and Associated Disorders, 20, 6-15. https://doi.org/10.1097/01.wad.0000191420.61260.a8

[27] Lane, R.F., Dacks, P.A., Shineman, D.W. and Lane, H.M.F. (2013) Diverse Therapeutic Targets and Biomarkers for Alzheimer's Disease and Related Dementias: Report on the Alzheimer's Drug Discovery Foundation 2012 International Conference on Alzheimer's Drug Discovery. Alzheimer's Research \& Therapy, 5, 5-9. https://doi.org/10.1186/alzrt159

[28] Vos, S.J.B., Gordon, B.A., Su, Y., Visser, P.J., Holtzman, D.M., Morris, J.C., Fagan, A.M. and Benzinger, T.L.S. (2016) NIA-AA Staging of Preclinical Alzheimer Disease: Discordance and Concordance of CSF and Imaging Biomarkers. Neurobiology of Aging, 44, 1-8. https://doi.org/10.1016/j.neurobiolaging.2016.03.025

[29] Proitsi, P., Kim, M., Whiley, L., Simmons, A., Sattlecker, M., Velayudhan, L., Lupton, M.K., Soininen, H., Kloszewska, I., Mecocci, P., Tsolaki, M., Vellas, B., Lovestone, S., Powell, J.F., Dobson, R.J. and Legido-Quigley, C. (2017) Association of Blood Lipids with Alzheimer's Disease: A Comprehensive Lipidomics Analysis. Alzheimer's \& Dementia, 13, 140-151. https://doi.org/10.1016/j.jalz.2016.08.003

[30] Yilmaz, A., Geddes, T., Han, B., Bahado-Singh, R.O., Wilson, G.D., Imam, K., Maddens, M. and Graham, S.F. (2017) Diagnostic Biomarkers of Alzheimer's Disease as Identified in Saliva Using 1H NMR-Based Metabolomics. Journal of Alzheimer's Disease, 58, 355-359. https://doi.org/10.3233/JAD-161226

[31] Blennow, K., Mattsson, N., Schöll, M., Hansson, O. and Zetterberg, H. (2015) Amyloid Biomarkers in Alzheimer's Disease. Trends in Pharmacological Sciences, 36, 297-309. https://doi.org/10.1016/j.tips.2015.03.002

[32] Nabers, A., Ollesch, J., Schartner, J., Kötting, C., Genius, J., Hafermann, H., Klafki, H., Gerwert, K., Wiltfang, J. and Gerwert, K. (2016) Amyloid- $\beta$-Secondary Structure Distribution in Cerebrospinal Fluid and Blood Measured by an Immuno-Infrared-Sensor: A Biomarker Candidate for Alzheimer's Disease. Analytical Chemistry, 88, 2755-2762. https://doi.org/10.1021/acs.analchem.5b04286

[33] Nakamura, A., Kaneko, N., Villemagne, V.L., Kato, T., Doecke, J., Doré, V., Fowler, C., Li, Q.-X., Martins, R., Rowe, C., Tomita, T., Matsuzaki, K., Ishii, K., Ishii, K., Arahata, Y., Iwamoto, S., Ito, K., Tanaka, K., Masters, C.L. and Yanagisawa, K. (2018) High Performance Plasma Amyloid- $\beta$ Biomarkers for Alzheimer's Disease. Nature, 554, 249-254. https://doi.org/10.1038/nature25456

[34] Ovod, V., Ramsey, K.N., Mawuenyega, K.G., Bollinger, J.G., Hicks, T., Schneider, T., Sullivan, M., Paumier, K., Holtzman, D.M., Morris, J.C., Benzinger, T., Fagan, A.M., Patterson, B.W. and Bateman, R.J. (2017) Amyloid $\beta$ Concentrations and Stable Isotope Labeling Kinetics of Human Plasma Specific to Central Nervous System Amyloidosis. Alzheimer's Dementia, 13, 841-849. https://doi.org/10.1016/j.jalz.2017.06.2266

[35] Lad E.M., Mukherjee, D., Stinnett, S.S., Cousins, S.W., Potter, G.G., Burke, J.R., Farsiu, S. and Whitson, H.E. (2018) Evaluation of Inner Retinal Layers as Biomarkers in Mild Cognitive Impairment to Moderate Alzheimer's Disease. PLoS ONE, 13, e0192646. https://doi.org/10.1371/journal.pone.0192646

[36] Kreisl, W.C., Henter, I.D. and Innis, R.B. (2018) Imaging Translocator Protein as a 
Biomarker of Neuroinflammation in Dementia. Advances in Pharmacology, 82, 163-185. https://doi.org/10.1016/bs.apha.2017.08.004

[37] Lu, J., Shu, R. and Zhu, Y. (2018) Dysregulation and Dislocation of SFPQ Disturbed DNA Organization in Alzheimer's Disease and Frontotemporal Dementia. Journal of Alzheimer's Disease, 61, 1311-1321. https://doi.org/10.3233/JAD-170659

[38] Gurel, B., Cansev, M., Sevinc, C., Kelestemur, S., Ocalan, B., Cakir, A., Aydin, S., Kahveci, N., Ozansoy, M., Taskapilioglu, O., Ulus, I.H., Başar, M.K., Sahin, B., Tuzuner, M.B. and Baykal, A.T. (2018) Early Stage Alterations in CA1 Extracellular Region Proteins Indicate Dysregulation of IL6 and Iron Homeostasis in the 5XFAD Alzheimer's Disease Mouse Model. Journal of Alzheimer's Disease, 61, 1399-1410. https://doi.org/10.3233/JAD-170329

[39] Xia, H., Wu, L., Chu, M., Feng, H., Lu, C. and Wang, Q. (2017) Effects of Breviscapine on Amyloid Beta 1-42 Induced Alzheimer's Disease Mice: A HPLC-QTOF-MS Based Plasma Metabonomics Study. Journal of Chromatography B, 1057, 92-100. https://doi.org/10.1016/j.jchromb.2017.05.003

[40] Jian, C., Lu, M., Zhang, Z., Liu, L., Li, X., Huang, F., Xu, N., Qin, L., Zhang, Q. and Zou, D. (2017) MiR-34a Knockout Attenuates Cognitive Deficits in APP/PS1 Mice through Inhibition of the Amyloidogenic Processing of APP. Life Sciences, 182, 104-111. https://doi.org/10.1016/j.lfs.2017.05.023

[41] Xu, Y., Li, X., Wang, X., Yao, J. and Zhuang, S. (2018) MiR-34a Deficiency in APP/PS1 Mice Promotes Cognitive Function by Increasing Synaptic Plasticity via AMPA and NMDA Receptors. Neuroscience Letters, 670, 94-104. https://doi.org/10.1016/j.neulet.2018.01.045

[42] Morphy, R. and Rankovic, Z. (2005) Designed Multiple Ligands. An Emerging Drug Discovery Paradigm. Journal of Medicinal Chemistry, 48, 6523-6543. https://doi.org/10.1021/jm058225d

[43] Rosini, M., Simoni, E., Caporaso, R. and Minarini, A. (2016) Multitarget Strategies in Alzheimer's Disease: Benefits and Challenges on the Road to Therapeutics. $\mathrm{Fu}^{-}$ ture Medicinal Chemistry, 8, 697-711. https://doi.org/10.4155/fmc-2016-0003

[44] Prati, F., Cavalli, A. and Bolognesi, M.L. (2016) Navigating the Chemical Space of Multitarget-Directed Ligands: From Hybrids to Fragments in Alzheimer's Disease. Molecules, 21, 466-478. https://doi.org/10.3390/molecules21040466

[45] Spilovska, K., Korabecny, J., Nepovimova, E., Dolezal, R., Mezeiova, E., Soukup, O. and Kuca, K. (2017) Multitarget Tacrine Hybrids with Neuroprotective Properties to Confront Alzheimer's Disease. Current Topics in Medicinal Chemistry, 17, 1006-1026. https://doi.org/10.2174/1568026605666160927152728

[46] Mohamed, T., Shakeri, A. and Rao, P.P.N. (2016) Amyloid Cascade in Alzheimer's Disease: Recent Advances in Medicinal Chemistry. European Journal of Medicinal Chemistry, 113, 258-272. https://doi.org/10.1016/j.ejmech.2016.02.049

[47] Ismaili, L., Refouvelet, B., Benchekroun, M., Brogi, S., Brindisi, M., Gemma, S., Campiani, G., Filipic, S., Agbaba, D. and Esteban, G. (2017) Multitarget Compounds Bearing Tacrine- and Donepezil-Like Structural and Functional Motifs for the Potential Treatment of Alzheimer's Disease. Progress in Neurobiology, 151, 4-34. https://doi.org/10.1016/j.pneurobio.2015.12.003

[48] Mohamed, T. and Rao, P.P.N. (2017) 2,4-Disubstituted Quinazolines as Amyloid- $\beta$ Aggregation Inhibitors with Dual Cholinesterase Inhibition and Antioxidant Properties: Development and Structure-Activity Relationship (SAR) Studies. European Journal of Medicinal Chemistry, 126, 823-843. https://doi.org/10.1016/j.ejmech.2016.12.005 
[49] Sola, I., Aso, E., Frattini, D., López-González, I., Espargaró, A., Sabaté, R., Di Pietro, O., Luque, F.J., Clos, M.V. and Ferrer, I. (2015) Novel Levetiracetam Derivatives That Are Effective against the Alzheimer-Like Phenotype in Mice: Synthesis, in Vitro, ex Vivo, and in Vivo Efficacy Studies. Journal of Medicinal Chemistry, 58, 6018-6032. https://doi.org/10.1021/acs.jmedchem.5b00624

[50] Darras, F.H., Pockes, S., Huang, G., Wehle, S., Strasser, A., Wittmann, H.-J., Nimczick, M., Sotriffer, C.A. and Decker, M. (2014) Synthesis, Biological Evaluation, and Computational Studies of Tri- and Tetracyclic Nitrogen-Bridgehead Compounds as Potent Dual-Acting AChE Inhibitors and hH3 Receptor Antagonists. ACS Chemical Neuroscience, 5, 225-242. https://doi.org/10.1021/cn4002126

[51] Bautista-Aguilera, Ó.M., Hagenow, S., Palomino-Antolin, A., Farré-Alins, V., Ismaili, L., Joffrin, P.-L., Jimeno, M.L. Soukup, O., Janocková, J. and Kalinowsky, L. (2017) Multitarget-Directed Ligands Combining Cholinesterase and Monoamine Oxidase Inhibition with Histamine H3R Antagonism for Neurodegenerative Diseases. Angewandte Chemie International Edition, 56, 12765-12769. https://doi.org/10.1002/anie.201706072

[52] Rochais, C., Lecoutey, C., Gaven, F., Giannoni, P., Hamidouche, K., Hedou, D., Dubost, E., Genest, D., Yahiaoui, S., Freret, T., Bouet, V., Dauphin, F., Sopkova de Oliveira Santos, J., Ballandonne, C., Corvaisier, S., Malzert-Fréon, A., Legay, R., Boulouard, M., Claeysen, S. and Dallemagne, P. (2015) Novel Multitarget-Directed Ligands (MTDLs) with Acetylcholinesterase (AChE) Inhibitory and Serotonergic Subtype 4 Receptor (5-HT4R) Agonist Activities as Potential Agents against Alzheimer's Disease: The Design of Donecopride. Journal of Medicinal Chemistry, 58, 3172-3187. https://doi.org/10.1021/acs.jmedchem.5b00115

[53] Wang, Z., Hu, J., Yang, X., Feng, X., Li, X., Huang, L. and Chan, A.S.C. (2018) Design, Synthesis and Evaluation of Orally Bioavailable Quinoline-Indole Derivatives as Innovative Multitarget-Directed Ligands: Promotion of Cell Proliferation in the Adult Murine Hippocampus for the Treatment of Alzheimer's Disease. Journal of Medicinal Chemistry, 61, 1871-1894.

https://doi.org/10.1021/acs.jmedchem.7b01417

[54] Esteban, G., Van Schoors, J., Sun, P., Van Eeckhaut, A., Marco-Contelles, J., Smolders, I. and Unzeta, M. (2017) In-Vitro and In-Vivo Evaluation of the Modulatory Effects of the Multitarget Compound ASS234 on the Monoaminergic System. Journal of Pharmacy and Pharmacology, 69, 314-324.

https://doi.org/10.1111/jphp.12697

[55] De Jaeger, X., Cammarota, M., Prado, M.A., Izquierdo, I., Prado, V.F. and Pereira, G.S. (2013) Decreased Acetylcholine Release Delays the Consolidation of Object Recognition Memory. Behavioural Brain Research, 238, 62-68. https://doi.org/10.1016/j.bbr.2012.10.016

[56] Zemek, F., Drtinova, L., Nepovimova, E., Sepsova, V., Korabecny, J., Klimes, J. and Kuca, K. (2014) Outcomes of Alzheimer's Disease Therapy with Acetylcholinesterase Inhibitors and Memantine. Expert Opinion on Drug Safety, 13, 759-774.

[57] Lemes, L.F.N., Ramos, G.D.A., Oliveira, A.S.D., Silva, F.M.R.D., Couto, G.D.C., Boni, M.D.S., Guimarães, M.J.R., Souza, I.N.O., Bartolini, M., Andrisano, V., do Nascimento Nogueira, P.C., Silveira, E.R., Brand, G.D., Soukup, O., Korábečný, J., Romeiro, N.C., Castro, N.G., Bolognesi, M.L. and Romeiro, L.A.S. (2016) Cardanol-Derived AChE Inhibitors: Towards the Development of Dual Binding Derivatives for Alzheimer's Disease. European Journal of Medicinal Chemistry, 108, 687-700. https://doi.org/10.1016/j.ejmech.2015.12.024

[58] Holzgrabe, U., Kapkova, P., Alptuzun, V., Scheiber, J. and Kugelmann, E. (2007) 
Targeting Acetyl Cholinesterase to Treat Neurodegeneration. Expert Opinion on Therapeutic Targets, 11, 161-179. https://doi.org/10.1517/14728222.11.2.161

[59] Korabecny, J., Musilek, K., Zemek, F., Horova, A., Holas, O., Nepovimova, E., Opletalova, V., Hroudova, J., Fisar, Z., Jung, Y.S. and Kuca, K. (2011) Synthesis and in Vitro Evaluation of 7-Methoxy- $N$-(Pent-4-Enyl)-1,2,3,4-Tetrahydroacridin-9-Amine-New Tacrine Derivate with Cholinergic Properties. Bioorganic and Medicinal Chemistry Letters, 21, 6563-6566. https://doi.org/10.1016/j.bmcl.2011.08.042

[60] Galimberti, D. and Scarpini, E. (2016) Old and New Acetylcholinesterase Inhibitors for Alzheimer's Disease. Expert Opinion on Investigational Drugs, 25, 1181-1187. https://doi.org/10.1080/13543784.2016.1216972

[61] Giacobini, E. (2003) Cholinesterases: New Roles in Brain Function and in Alzheimer's Disease. Neurochemical Research, 28, 515-522.

https://doi.org/10.1023/A:1022869222652

[62] Greig, N.H., Lahiri, D.K. and Sambamurti, K. (2002) Butyrylcholinesterase: An Important New Target in Alzheimer's Disease Therapy. International Psychogeriatrics, 14, 77-91. https://doi.org/10.1017/S1041610203008676

[63] Terry Jr., A.V. and Buccafusco, J.J. (2003) The Cholinergic Hypothesis of Age and Alzheimer's Disease-Related Cognitive Deficits: Recent Challenges and Their Implications for Novel Drug Development. Journal of Pharmacology and Experimental Therapeutics, 306, 821-827. https://doi.org/10.1124/jpet.102.041616

[64] Bajda, M., Guzior, N., Ignasik, M. and Malawska, B. (2011) Multi-Target Directed Ligands in Alzheimer's Disease Treatment. Current Medicinal Chemistry, 18, 4949-4975. https://doi.org/10.2174/092986711797535245

[65] Babkova, K., Korabecny, J., Soukup, O., Nepovimova, E., Jun, D. and Kuca, K. (2017) Prolyl Oligopeptidase and Its Role in the Organism: Attention to the Most Promising and Clinically Relevant Inhibitors. Future Medicinal Chemistry, 9, 1015-1038. https://doi.org/10.4155/fmc-2017-0030

[66] Cavalli, A., Bolognesi, M.L., Minarini, A., Rosini, M., Tumiatti, V., Recanatini, M. and Melchiorre, C. (2008) Multi-Target Directed Ligands to Combat Neurodegenerative Diseases. Journal of Medicinal Chemistry, 51, 347-372.

https://doi.org/10.1021/jm7009364

[67] Wang, Y., Wang, H. and Chen, H.Z. (2016) AChE Inhibition-Based Multi-Target-Directed Ligands: A Novel Pharmacological Approach for the Symptomatic and Disease-Modifying Therapy of Alzheimer's Disease. Current Neuropharmacology, 14, 364-375. https://doi.org/10.2174/1570159X14666160119094820

[68] Bolognesi, M.L., Rosini, M., Andrisano, V., Bartolini, M., Minarini, A., Tumiatti, V. and Melchiorre, C. (2009) MTDL Design Strategy in the Context of Alzheimer's Disease: From Lipocrine to Memoquin and Beyond. Current Pharmaceutical Design, 15, 601-613. https://doi.org/10.2174/138161209787315585

[69] Bolognesi, M.L., Minarini, A., Rosini, M., Tumiatti, V. and Melchiorre, C. (2008) From Dual Binding Site Acetylcholinesterase Inhibitors to Multi-Target-Directed Ligands (MTDLs): A Step Forward in the Treatment of Alzheimer's Disease. Mini-Reviews in Medicinal Chemistry, 8, 960-967. https://doi.org/10.2174/138955708785740652

[70] Gazova, Z., Soukup, O., Sepsova, V., Drtinova, L., Jost, P., Spilovska, K., Korabecny, J., Nepovimova, E., Fedunova, D., Horak, M., Kaniakova, M., Wang, Z.J., Hamouda, A.K. and Kuca, K. (2017) Multi-Target-Directed Therapeutic Potential of 7-Methoxytacrine-Adamantylamineheterodimers in the Alzheimer's Disease Treatment. Biochimica et Biophysica Acta, 1863, 607-619. 
https://doi.org/10.1016/j.bbadis.2016.11.020

[71] Spilovska, K., Korabecny, J., Sepsova, V., Jun, D., Hrabinova, M., Jost, P., Muckova, L., Soukup, O., Janockova, J., Kucera, T., Dolezal, R., Mezeiova, E., Kaping, D. and Kuca, K. (2017) Novel Tacrine-Scutellarin Hybrids as Multipotent Anti-Alzheimer's Agents: Design, Synthesis and Biological Evaluation. Molecules, 22, 1006-1027. https://doi.org/10.3390/molecules22061006

[72] Viegas, F.P.D., Silva, M.D.F., Rocha, M.D.D., Castelli, M.R., Riquiel, M.M., Machado, R.P., Vaz, S.M., Simões de Lima, L.M., Mancini, K.C., Marques de Oliveira, P.C., Morais, É.P., Gontijo, V.S., da Silva, F.M.R., D’Alincourt da Fonseca Peçanha, D., Castro, N.G., Neves, G.A., Giusti-Paiva, A., Vilela, F.C., Orlandi, L., Camps, I., Veloso, M.P., Leomil Coelho, L.F., Ionta, M., Ferreira-Silva, G.Á., Pereira, R.M., Dardenne, L.E., Guedes, I.A., de Oliveira Carneiro Junior, W., Quaglio Bellozi, P.M., Pinheiro de Oliveira, A.C., Ferreira, F.F., Pruccoli, L., Tarozzi, A. and Viegas Jr., C. (2018) Design, Synthesis and Pharmacological Evaluation of N-Benzyl-Piperidinyl-Aryl-Acylhydrazone Derivatives as Donepezil Hybrids: Discovery of Novel Multi-Target Anti-Alzheimer Prototype Drug Candidates. European Journal of Medicinal Chemistry, 147, 48-65. https://doi.org/10.1016/j.ejmech.2018.01.066

[73] Zhang, W., Huang, D., Huang, M., Huang, J., Wang, D., Liu, X., Nguyen, M., Vendier, L., Mazères, S., Robert, A., Liu, Y. and Meunier, B. (2018) Preparation of New Tetradentate Copper Chelators as Potential Anti-Alzheimer Agents. ChemMedChem, 13, 684-704. https://doi.org/10.1002/cmdc.201700734

[74] Selkoe, D.J. (1991) Amyloid Protein and Alzheimer's Disease. Scientific American, 265, 68-71. https://doi.org/10.1038/scientificamerican1191-68

[75] Vassar, R., Bennett, B.D., Babu-Khan, S., Kahn, S., Mendiaz, E.A., Denis, P., Teplow, D.B., Ross, S., Amarante, P., Loeloff, R., Luo, Y., Fisher, S., Fuller, J., Edenson, S., Lile, J., Jarosinski, M.A., Biere, A.L., Curran, E., Burgess, T., Louis, J.C., Collins, F., Treanor, J., Rogers, G. and Citron, M. (1999) $\beta$-Secretase Cleavage of Alzheimer's Amyloid Precursor Protein by the Transmembrane Aspartic Protease BACE. Science, 286, 735-741. https://doi.org/10.1126/science.286.5440.735

[76] Yan, R., Bienkowski, M.J., Shuck, M.E., Miao, H., Tory, M.C., Pauley, A.M., Brashier, J.R., Stratman, N.C., Mathews, W.R., Buhl, A.E., Carter, D.B., Tomasselli, A.G., Parodi, L.A., Heinrikson, R.L. and Gurney, M.E. (1999) Membrane Anchored Aspartyl Protease with Alzheimer's Disease $\beta$-Secretase Activity. Nature, 402, 533-537. https://doi.org/10.1038/990107

[77] Roberds, S.L., Anderson, J., Basi, G., Bienkowski, M.J., Branstetter, D.G., Chen, K.S., Freedman, S.B., Frigon, N.L., Games, D., Hu, K., Johnson-Wood, K., Kappenman, K.E., Kawabe, T.T., Kola, I., Kuehn, R., Lee, M., Liu, W., Motter, R., Nichols, N.F., Power, M., Robertson, D.W., Schenk, D., Schoor, M., Shopp, G.M. Shuck, M.E., Sinha, S., Svensson, K.A., Tatsuno, G., Tintrup, H., Wijsman, J., Wright, S. and McConlogue, L. (2001) BACE Knockout Mice Are Healthy Despite Lacking the Primary $\beta$-Secretase Activity in Brain: Implications for Alzheimer's Disease Therapeutics. Human Molecular Genetics, 10, 1317-1324. https://doi.org/10.1093/hmg/10.12.1317

[78] Luo, Y., Bolon, B., Kahn, S., Bennett, B.D., Babu-Khan, S., Denis, P., Fan, W., Kha, H., Zhang, J., Gong, Y., Martin, L., Louis, J.C., Yan, Q., Richards, W.G., Citron, M. and Vassar, R. (2001) Mice Deficient in BACE1, the Alzheimer's $\beta$-Secretase, Have Normal Phenotype and Abolished $\beta$-Amyloid Generation. Nature Neuroscience, 4 , 231-232. https://doi.org/10.1038/85059

[79] Ohno, M., Chang, L., Tseng, W., Oakley, H., Citron, M., Klein, W.L., Vassar, R. and Disterhoft, J.F. (2006) Temporal Memory Deficits in Alzheimer's Mouse Models: 
Rescue by Genetic Deletion of BACE1. European Journal of Neuroscience, 23, 251-260. https://doi.org/10.1111/j.1460-9568.2005.04551.x

[80] Ohno, M., Sametsky, E.A., Younkin, L.H., Oakley, H., Younkin, S.G., Citron, M., Vassar, R. and Disterhoft, J.F. (2004) BACE1deficiency Rescues Memory Deficits and Cholinergic Dysfunction in a Mouse Model of Alzheimer's Disease. Neuron, 41, 27-33. https://doi.org/10.1016/S0896-6273(03)00810-9

[81] Michalik, L., Auwerx, J., Berger, J.P., Chatterjee, V.K., Glass, C.K., Gonzalez, F.J., Grimaldi, P.A., Kadowaki, T., Lazar, M.A., O’Rahilly, S., Palmer, C.N., Plutzky, J., Reddy, J.K., Spiegelman, B.M., Staels, B. and Wahli, W. (2006) International Union of Pharmacology. LXI. Peroxisome Proliferator-Activated Receptors. Pharmacological Reviews, 58, 726-741. https://doi.org/10.1124/pr.58.4.5

[82] Mandrekar-Colucci, S., Karlo, J.C. and Landreth, G.E. (2012) Mechanisms Underlying the Rapid Peroxisome Proliferator Activated Receptor- $\gamma$-Mediated Amyloid Clearance and Reversal of Cognitive Deficits in a Murine Model of Alzheimer's Disease. The Journal of Neuroscience, 32, 10117-10128. https://doi.org/10.1523/JNEUROSCI.5268-11.2012

[83] Landreth, G., Jiang, Q., Mandrekar, S. and Heneka, M. (2008) PPAR $\gamma$ Agonists as Therapeutics for the Treatment of Alzheimer's Disease. Neurotherapeutics, 5, 481-489. https://doi.org/10.1016/j.nurt.2008.05.003

[84] Craft, S. (2009) The Role of Metabolic Disorders in Alzheimer Disease and Vascular Dementia: Two Roads Converged. Archives of Neurology, 66, 300-305. https://doi.org/10.1001/archneurol.2009.27

[85] Buse, J.B. (2007) Action to Control Cardiovascular Risk in Diabetes. The American Journal of Cardiology, 99, S21-S33. https://doi.org/10.1016/j.amjcard.2007.03.003

[86] Vassar, R. (2014) BACE1 Inhibitor Drugs in Clinical Trials for Alzheimer's Disease. Alzheimer's Research \& Therapy, 6, 89-103. https://doi.org/10.1186/s13195-014-0089-7

[87] Luo, X. and Yan, R. (2010) Inhibition of BACE1 for Therapeutic Use in Alzheimer's Disease. International Journal of Clinical and Experimental Pathology, 3, 618-628.

[88] May, P.C., Willis, B.A., Lowe, S.L., Dean, R.A., Monk, S.A., Cocke, P.J., Audia, J.E., Boggs, L.N., Borders, A.R., Brier, R.A., Calligaro, D.O., Day, T.A., Ereshefsky, L., Erickson, J.A., Gevorkyan, H., Gonzales, C.R., James, D.E., Jhee, S.S., Komjathy, S.F., Li, L., Lindstrom, T.D., Mathes, B.M., Martényi, F., Sheehan, S.M., Stout, S.L., Timm, D.E., Vaught, G.M., Watson, B.M., Winneroski, L.L., Yang, Z. and Mergott, D.J. (2015) The Potent BACE1 Inhibitor LY2886721 Elicits Robust Central a Beta Pharmacodynamic Responses in Mice, Dogs, and Humans. Journal of Neuroscience, 35, 1199-1210. https://doi.org/10.1523/JNEUROSCI.4129-14.2015

[89] Sparve, E., Quartino, A.L., Luttgen, M., Tunblad, K., Gårdlund, A.T., Fälting, J., Alexander, R, Kågström, J., Sjödin, L., Bulgak, A., Al-Saffar, A., Bridgland-Taylor, M., Pollard, C., Swedberg, M.D., Vik, T. and Paulsson, B. (2014) Prediction and Modeling of Effects on the QTc Interval for Clinical Safety Margin Assessment Based on Single-Ascending Dose Study Data with AZD3839. Journal of Pharmacology and Experimental Therapeutics, 350, 469-478. https://doi.org/10.1124/jpet.114.215202

[90] Kim, H.G., Moon, M., Choi, J.G., Park, G., Kim, A.J., Hur, J., Lee, K.T. and Oh, M.S. (2014) Donepezil Inhibits the Amyloid-Beta Oligomer-Induced Microglial Activation in Vitro and in Vivo. NeuroToxicology, 40, 23-32.

https://doi.org/10.1016/j.neuro.2013.10.004

[91] Ma, Y., Ji, J., Li, G., Yang, S. and Pan, S. (2018) Effects of Donepezil on Cognitive Functions and the Expression Level of $\beta$-Amyloid in Peripheral Blood of Patients 
with Alzheimer's Disease. Experimental and Therapeutic Medicine, 15, 1875-1878.

[92] Nagakura, A., Shitaka, Y., Yarimizu, J. and Matsuoka, N. (2013) Characterization of Cognitive Deficits in a Transgenic Mouse Model of Alzheimer's Disease and Effects of Donepezil and Memantine. European Journal of Pharmacology, 703, 53-61. https://doi.org/10.1016/j.ejphar.2012.12.023

[93] Ye, C.Y., Lei, Y., Tang, X.C. and Zhang, H.Y. (2015) Donepezil Attenuates Af3-Associated Mitochondrial Dysfunction and Reduces Mitochondrial Af3 Accumulation in Vivo and in Vitro. Neuropharmacology, 95, 29-36. https://doi.org/10.1016/j.neuropharm.2015.02.020

[94] Bhattacharya, S., Maelicke, A. and Montag, D. (2015) Nasal Application of the Galantamine Pro-Drug Memogain Slows down Plaque Deposition and Ameliorates Behavior in 5X Familial Alzheimer's Disease Mice. Journal of Alzheimer's Disease, 46, 123-136. https://doi.org/10.3233/JAD-142421

[95] Singh, M., Kaur, M., Singh, N. and Silakari, O. (2017) Exploration of Multi-Target Potential of Chromen-4-One Based Compounds in Alzheimer's Disease: Design, Synthesis and Biological Evaluations. Bioorganic \& Medicinal Chemistry, 25, 6273-6285. https://doi.org/10.1016/j.bmc.2017.09.012

[96] Zueva, I.V., Semenov, V.E., Mukhamedyarov, M.A., Lushchekina, S.V., Kharlamova, A.D., Petukhova, E.O., Mikhailov, A.S., Podyachev, S.N., Saifina, L.F., Petrov, K.A., Minnekhanova, O.A., Zobov, V.V., Nikolsky, E.E., Masson, P. and Reznik, V.S. (2015) 6-Methyluracil Derivatives as Acetylcholinesterase Inhibitors for Treatment of Alzheimer's Disease. International Journal of Risk \& Safety in Medicine, 27, 69-71. https://doi.org/10.3233/JRS-150694

[97] Deng, M., Huang, L., Ning, B., Wang, N., Zhang, Q., Zhu, C. and Fang, Y. (2016) $\beta$-Asarone Improves Learning and Memory and Reduces Acetyl Cholinesterase and Beta-Amyloid 42 Levels in APP/PS1 Transgenic Mice by Regulating Beclin-1-Dependent Autophagy. Brain Research, 1652, 188-194. https://doi.org/10.1016/j.brainres.2016.10.008

[98] Panzella, L., Eidenberger, T. and Napolitano, A. (2018) Anti-Amyloid Aggregation Activity of Black Sesame Pigment: Toward a Novel Alzheimer's Disease Preventive Agent. Molecules, 23, 676-689. https://doi.org/10.3390/molecules23030676

[99] Jiang, L., Huang, M., Xu, S., Wang, Y., An, P., Feng, C., Chen, X., Wei, X., Han, Y. and Wang, Q. (2016) Bis(Propyl)-Cognitin Prevents $\beta$-Amyloid-Induced Memory Deficits as Well as Synaptic Formation and Plasticity Impairments via the Activation of PI3-K Pathway. Molecular Neurobiology, 53, 3832-3841. https://doi.org/10.1007/s12035-015-9317-9

[100] Chang, L., Cui, W., Yang, Y., Xu, S., Zhou, W., Fu, H., Hu, S., Mak, S., Hu, J., Wang, Q., Ma, V.P., Choi, T.C., Ma, E.D., Tao, L., Pang, Y., Rowan. M.J., Anwyl, R., Han, Y. and Wang, Q. (2015) Protection against $\beta$-Amyloid-Induced Synaptic and Memory Impairments via Altering $\beta$-Amyloid Assembly by Bis(Heptyl)-Cognitin. Scientific Reports, 5, Article No. 10256. https://doi.org/10.1038/srep10256

[101] Gu, X.H., Xu, L.J., Liu, Z.Q., Wei, B., Yang, Y.J., Xu, G.G., Yin, X.P. and Wang, W. (2016) The Flavonoid Baicalein Rescues Synaptic Plasticity and Memory Deficits in a Mouse Model of Alzheimer's Disease. Behavioural Brain Research, 15, 309-321. https://doi.org/10.1016/j.bbr.2016.05.052

[102] Tian, T., Bai, D., Li, W., Huang, G.W. and Liu, H. (2016) Effects of Folic Acid on Secretases Involved in a $\beta$ Deposition in APP/PS1 Mice. Nutrients, 8, 556-567. https://doi.org/10.3390/nu8090556

[103] Nishiyama, S., Ohba, H., Kanazawa, M., Kakiuchi, T. and Tsukada, H. (2015) Com- 
paring $\alpha 7$ Nicotinic Acetylcholine Receptor Binding, Amyloid- $\beta$ Deposition, and Mitochondria Complex-I Function in Living Brain: A PET Study in Aged Monkeys. Synapse, 69, 475-483. https://doi.org/10.1002/syn.21842

[104] Nakaizumi, K., Ouchi, Y., Terada, T., Yoshikawa, E., Kakimoto, A., Isobe, T., Bunai, T., Yokokura, M., Suzuki, K. and Magata, Y. (2018) In Vivo Depiction of $a 7$ Nicotinic Receptor Loss for Cognitive Decline in Alzheimer's Disease. Journal of Alzheimer's Disease, 61, 1355-1365. https://doi.org/10.3233/JAD-170591

[105] Panek, D., Więckowska, A., Pasieka, A., Godyń, J., Jończyk, J., Bajda, M., Knez, D., Gobec, S. and Malawska, B. (2018) Design, Synthesis, and Biological Evaluation of 2-(Benzylamino-2-Hydroxyalkyl) Isoindosline-1,3-Diones Derivatives as Potential Disease-Modifying Multifunctional Anti-Alzheimer Agents. Molecules, 23, 347-357. https://doi.org/10.3390/molecules23020347

[106] Kidana, K., Tatebe, T., Ito, K., Hara, N., Kakita, A., Saito, T., Takatori, S., Ouchi, Y., Ikeuchi, T., Makino, M., Saido, T.C., Akishita, M., Iwatsubo, T., Hori, Y. and Tomita, T. (2018) Loss of Kallikrein-Related Peptidase 7 Exacerbates Amyloid Pathology in Alzheimer's Disease Model Mice. EMBO Molecular Medicine, 10, 8184-8197. https://doi.org/10.15252/emmm.201708184

[107] Kumar, R.S., Almansour, A.I., Arumugam, N., Althomili, D.M.Q., Altaf, M., Basiri, A.D.K. and Sai Manohar, T.S.V. (2018) Ionic Liquid-Enabled Synthesis, Cholinesterase Inhibitory Activity, and Molecular Docking Study of Highly Functionalized Tetrasubstituted Pyrrolidines. Bioorganic Chemistry, 77, 263-268. https://doi.org/10.1016/j.bioorg.2018.01.019

[108] Pitt, J., Wilcox, K.C., Tortelli, V., Diniz, L.P., Oliveira, M.S., Dobbins, C., Yu, X.W., Nandamuri, S., Gomes, F.C.A., DiNunno, N., Viola, K.L., De Felice, F.G., Ferreira, S.T. and Klein, W.L. (2017) Neuroprotective Astrocyte-Derived Insulin/Insulin-Like Growth Factor 1 Stimulates Endocytic Processing and Extracellular Release of Neuron-Bound A $\beta$ Oligomers. Molecular Biology of the Cell, 28, 2623-2636. https://doi.org/10.1091/mbc.e17-06-0416

[109] Um, J.W., Kaufman, A.C., Kostylev, M., Heiss, J.K., Stagi, M., Takahashi, H., Kerrisk, M.E., Vortmeyer, A., Wisniewski, T., Koleske, A.J., Gunther, E.C., Nygaard, H.B. and Strittmatter, S.M. (2013) Metabotropic Glutamate Receptor 5 Is a Coreceptor for Alzheimer A $\beta$ Oligomer Bound to Cellular Prion Protein. Neuron, 79, 887-902. https://doi.org/10.1016/j.neuron.2013.06.036

[110] Haas, L.T., Kostylev, M.A. and Strittmatter, S.M. (2014) Therapeutic Molecules and Endogenous Ligands Regulate the Interaction between Brain Cellular Prion Protein (PrPC) and Metabotropic Glutamate Receptor 5 (mGluR5). The Journal of Biological Chemistry, 289, 8460-8477. https://doi.org/10.1074/jbc.M114.584342

[111] Ostapchenko, V.G., Beraldo, F.H., Mohammad, A.H., Xie, Y.F., Hirata, P.H., Magalhaes, A.C., Lamour, G., Li, H., Maciejewski, A., Belrose, J.C., Teixeira, B.L., Fahnestock, M., Ferreira, S.T., Cashman, N.R., Hajj, G.N., Jackson, M.F., Choy, W.Y., MacDonald, J.F., Martins, V.R., Prado, V.F., Prado, M.A. (2013) The Prion Protein Ligand, Stress-Inducible Phosphoprotein 1, Regulates Amyloid- $\beta$ Oligomer Toxicity. Journal of Neuroscience, 33, 16552-16564. https://doi.org/10.1523/JNEUROSCI.3214-13.2013

[112] Maciejewski, A., Ostapchenko, V.G., Beraldo, F.H., Prado, V.F., Prado, M.A. and Choy, W.Y. (2016) Domains of STIP1 Responsible for Regulating $\operatorname{PrP}^{\mathrm{C}}$-Dependent Amyloid- $\beta$ Oligomer Toxicity. Biochemical Journal, 473, 2119-2130. https://doi.org/10.1042/BCJ20160087

[113] Dai, X., Chang, P., Li, X., Gao, Z. and Sun, Y. (2018) The Inhibitory Effect of Chitosan Oligosaccharides on $\beta$-Site Amyloid Precursor Protein Cleaving Enzyme 1 
(BACE1) in HEK293 APPswe Cells. Neuroscience Letters, 665, 80-85. https://doi.org/10.1016/j.neulet.2017.11.052

[114] Wang, S., Liu, D., Zhang, L., Ji, M., Zhang, Y., Dong, Q., Liu, S., Xie, X. and Liu, R. (2017) A Vaccine with A $\beta$ Oligomer-Specific Mimotope Attenuates Cognitive Deficits and Brain Pathologies in Transgenic Mice with Alzheimer's Disease. Alzheimer's Research \& Therapy, 9, 41-55. https://doi.org/10.1186/s13195-017-0267-5

[115] Giannoni, P., Gaven, F., de Bundel, D., Baranger, K., Marchetti-Gauthier, E., Roman, F.S., Valjent, E., Marin, P., Bockaert, J., Rivera, S. and Claeysen, S. (2013) Early Administration of RS 67333, a Specific 5-HT4 Receptor Agonist, Prevents Amyloidogenesis and Behavioral Deficits in the 5XFAD Mouse Model of Alzheimer's Disease. Frontiers in Aging Neuroscience, 5, 96-108.

https://doi.org/10.3389/fnagi.2013.00096

[116] Jung, H.A., Ali, M.Y., Jung, H.J., Jeong, H.O., Chung, H.Y. and Choi, J.S. (2016) Inhibitory Activities of Major Anthraquinones and Other Constituents from Cassia obtusifolia against $\beta$-Secretase and Cholinesterases. Journal of Ethnopharmacology, 191, 152-160. https://doi.org/10.1016/j.jep.2016.06.037

[117] Kim, D.H., Yoon, B.H., Kim, Y.W., Lee, S., Shin, B.Y., Jung, J.W. and Ryu, J.H. (2007) The Seed Extract of Cassia obtusifolia Ameliorates Learning and Memory Impairments Induced by Scopolamine or Transient Cerebral Hypoperfusion in Mice. Journal of Pharmacological Sciences, 105, 82-93.

https://doi.org/10.1254/jphs.FP0061565

[118] Yi, J.H., Park, H.J., Lee, S., Jung, J.W., Kim, B.C., Lee, Y.C., Ryu, J.H. and Kim, D.H. (2016) Cassia obtusifolia Seed Ameliorates Amyloid $\beta$-Induced Synaptic Dysfunction through Anti-Inflammatory and Akt/GSK-3 $\beta$ Pathways. Journal of Ethnopharmacology, 178, 50-57. https://doi.org/10.1016/j.jep.2015.12.007

[119] Xu, S., Nigam, S.M. and Brodin, L. (2018) Overexpression of SNX3 Decreases Amyloid- $\beta$ Peptide Production by Reducing Internalization of Amyloid Precursor Protein. Neurodegenerative Diseases, 18, 26-37. https://doi.org/10.1159/000486199

[120] Esmaeili, M.H., Bahari, B. and Salari, A.A. (2018) ATP-Sensitive Potassium-Channel Inhibitor Glibenclamide Attenuates HPA Axis Hyperactivity, Depression- and Anxiety-Related Symptoms in a Rat Model of Alzheimer's Disease. Brain Research Bulletin, 137, 265-276. https://doi.org/10.1016/j.brainresbull.2018.01.001

[121] Ge, X., Yang, Y., Sun, Y., Cao, W. and Ding, F. (2018) Islet Amyloid Polypeptide Promotes Amyloid-Beta Aggregation by Binding-Induced Helix-Unfolding of the Amyloidogenic Core. ACS Chemical Neuroscience, 396-405. https://doi.org/10.1021/acschemneuro.7b00396

[122] Hall, H., Iulita, M.F., Gubert, P., Aguilar, L., Ducatenzeiler, A., Fisher, A. and Cuello, A.C. (2018) AF710B, an M1/Sigma-1 Receptor Agonist with Long-Lasting Disease-Modifying Properties in a Transgenic Rat Model of Alzheimer's Disease. Alzheimer's \& Dementia, 14, 811-823.

[123] Wang, J., Wang, C., Wu, Z., Li, X., Xu, S., Liu, J., Lan, Q., Zhu, Z. and Xu, J. (2018) Design, Synthesis, Biological Evaluation, and Docking Study of 4-Isochromanonehybrids Bearing $N$-Benzyl Pyridinium Moiety as Dual Binding Site Acetylcholinesterase Inhibitors (Part II). Chemical Biology \& Drug Design, 91, 756-762.

https://doi.org/10.1111/cbdd.13136

[124] Fisher, A., Bezprozvanny, I., Wu, L., Ryskamp, D.A., Bar-Ner, N., Natan, N., Brandeis, R., Elkon, H., Nahum, V., Gershonov, E., LaFerla, F.M. and Medeiros, R. (2016) AF710B, a Novel M1/ $\sigma$ l Agonist with Therapeutic Efficacy in Animal Models of Alzheimer's Disease. Neuro-Degenerative Diseases, 16, 95-110. 
https://doi.org/10.1159/000440864

[125] Clemens, V., Regen, F., Le Bret, N., Heuser, I. and Hellmann-Regen, J. (2018) Retinoic Acid Enhances Apolipoprotein E Synthesis in Human Macrophages. Journal of Alzheimer's Disease, 61, 1295-1300. https://doi.org/10.3233/JAD-170823

[126] Sanz Muñoz, S., Li, H., Ruberu, K., Chu, Q., Saghatelian, A., Ooi, L. and Garner, B. (2018) The Serine Protease HtrA1 Contributes to the Formation of an Extracellular $25-\mathrm{kDa}$ Apolipoprotein E Fragment That Stimulates Neuritogenesis. The Journal of Biological Chemistry, 293, 4071-4084. https://doi.org/10.1074/jbc.RA117.001278

[127] De Leon, M.J., Pirraglia, E., Osorio, R.S., Glodzik, L., Saint-Louis, L., Kim, H.J., Fortea, J., Fossati, S., Laska, E., Siegel, C., Butler, T., Li, Y., Rusinek, H., Zetterberg, H. and Blennow, K. (2018) The Nonlinear Relationship between Cerebrospinal Fluid A $\beta 42$ and Tau in Preclinical Alzheimer's Disease. PLoS ONE, 13, 0191240. https://doi.org/10.1371/journal.pone.0191240

[128] Chen, Y., Zhu, J., Mo,J., Yang, H., Jiang, X., Lin, H., Gu, K., Pei, Y., Wu, L., Tan, R., Hou, J., Chen, J., Lv, Y., Bian Y. and Sun, H. (2018) Synthesis and Bioevaluation of New Tacrine-Cinnamic Acid Hybrids as Cholinesterase Inhibitors against Alzheimer's Disease. Journal of Enzyme Inhibition and Medicinal Chemistry, 33, 290-302. https://doi.org/10.1080/14756366.2017.1412314

[129] Shih, J.C., Chen, K. and Ridd, M.J. (1999) Monoamine Oxidase: From Genes to Behavior. Annual Review of Neuroscience, 22, 197-217. https://doi.org/10.1146/annurev.neuro.22.1.197

[130] Mellick, G.D., Buchanan, D.D., McCann, S.J., James, K.M., Johnson, A.G., Davis, D.R., Liyou, N., Chan, D. and Le Couteur, D.G. (1999) Variations in the Monoamine Oxidase B (MAOB) Gene Are Associated with Parkinson's Disease. Movement Disorders, 14, 219-224. https://doi.org/10.1002/1531-8257(199903)14:2<219::AID-MDS1003>3.0.CO;2-9

[131] Edmondson, D.E., Mattevi, A., Binda, C., Li, M., Hubálek, F. (2004) Structure and Mechanism of Monoamine Oxidase. Current Medicinal Chemistry, 11, 1983-1993. https://doi.org/10.2174/0929867043364784

[132] Wouters, J. (1998) Structural Aspects of Monoamine Oxidase and Its Reversible Inhibition. Current Medicinal Chemistry, 5, 137-162.

[133] Youdim, M.B., Edmondson, D. and Tipton, K.F. (2006) The Therapeutic Potential of Monoamine Oxidase Inhibitors. Nature Reviews Neuroscience, 7, 295-309. https://doi.org/10.1038/nrn1883

[134] Adolfsson, R., Gottfries, C.G., Oreland, L., Wiberg, A. and Winblad, B. (1980) Increased Activity of Brain and Platelet Monoamine Oxidase in Dementia of Alzheimer Type. Life Sciences, 27, 1029-1034. https://doi.org/10.1016/0024-3205(80)90025-9

[135] Riederer, P., Danielczyk, W. and Grünblatt, E. (2004) Monoamine Oxidase-B Inhibition in Alzheimer's Disease. Neurotoxicology, 25, 271-277. https://doi.org/10.1016/S0161-813X(03)00106-2

[136] Chimenti, F., Secci, D., Bolasco, A., Chimenti, P., Bizzarri, B., Granese, A., Carradori, S., Yáñez, M., Orallo, F., Ortuso, F. and Alcaro, S. (2009) Synthesis, Molecular Modeling, and Selective Inhibitory Activity against Human Monoamine Oxidases of 3-Carboxamido-7-Substituted Coumarins. Journal of Medicinal Chemistry, 52, 1935-1942. https://doi.org/10.1021/jm801496u

[137] Matos, M.J., Terán, C., Pérez-Castillo, Y., Uriarte, E., Santana, L. and Viña, D. (2011) Synthesis and Study of a Series of 3-Arylcoumarins as Potent and Selective Monoamine Oxidase B Inhibitors. Journal of Medicinal Chemistry, 54, 7127-7137. 
https://doi.org/10.1021/jm200716y

[138] Bar-Am, O., Amit, T., Weinreb, O., Youdim, M.B. and Mandel, S. (2010) Propargylamine Containing Compounds as Modulators of Proteolytic Cleavage of Amyloid-Beta Protein Precursor: Involvement of MAPK and PKC Activation. Journal of Alzheimer's Disease, 21, 361-371. https://doi.org/10.3233/JAD-2010-100150

[139] Lee, H.J., Korshavn, K.J., Kochi, A., Derrick, J.S., Lim, M.H. (2014) Cholesterol and Metal Ions in Alzheimer's Disease. Chemical Society Reviews, 43, 6672-6682. https://doi.org/10.1039/C4CS00005F

[140] Molina-Holgado, F., Hider, R.C., Gaeta, A., Williams, R. and Francis, P. (2007) Metals Ions and Neurodegeneration. BioMetals, 20, 639-654. https://doi.org/10.1007/s10534-006-9033-z

[141] Syme, C.D., Nadal, R.C., Rigby, S.E.J. and Viles, J.H. (2004) Copper Binding to the Amyloid- $\beta(\mathrm{A} \beta)$ Peptide Associated with Alzheimer's Disease. Journal of Biological Chemistry, 279, 18169-18177. https://doi.org/10.1074/jbc.M313572200

[142] Hureau, C. and Faller, P. (2009) A Beta-Mediated ROS Production by Cu Ions: Structural Insights, Mechanisms and Relevance to Alzheimer's Disease. Biochimie, 91, 1212-1217. https://doi.org/10.1016/j.biochi.2009.03.013

[143] Himes, R.A., Park, G.Y., Siluvai, G.S., Blackburn, N.J. and Karlin, K.D. (2008) Structural Studies of Copper(I) Complexes of Amyloid- $\beta$ Peptide Fragments: Formation of Two Coordinate Bis(Histidine) Complexes. Angewandte Chemie International Edition, 47, 9084-9087. https://doi.org/10.1002/anie.200803908

[144] Hindo, S.S., Mancino, A.M., Braymer, J.J., Liu, Y., Vivekanandan, S., Ramamoorthy, A. and Lim, M.H. (2009) Small Molecule Modulators of Copper-Induced A Beta Aggregation. Journal of the American Chemical Society, 131, 16663-16665. https://doi.org/10.1021/ja907045h

[145] Rodriguez-Rodriguez, C., Telpoukhovskaia, M. and Orvig, C. (2012) The Art of Building Multifunctional Metal-Binding Agents from Basic Molecular Scaffolds for the Potential Application in Neurodegenerative Diseases. Coordination Chemistry Reviews, 256, 2308-2332. https://doi.org/10.1016/j.ccr.2012.03.008

[146] Pratico, D. (2008) Oxidative Stress Hypothesis in Alzheimer's Disease: A Reappraisal. Trends in Pharmacological Sciences, 29, 609-615. https://doi.org/10.1016/j.tips.2008.09.001

[147] Lee, H.P., Zhu, X., Casadesus, G., Castellani, R.J., Nunomura, A., Smith, M.A., Lee, H.G. and Perry, G. (2010) Antioxidant Approaches for the Treatment of Alzheimer's Disease. Expert Review of Neurotherapuetics, 10, 1201-1208. https://doi.org/10.1586/ern.10.74

[148] Dumont, M. and Beal, M.F. (2011) Neuroprotective Strategies Involving ROS in Alzheimer Disease. Free Radical Biology and Medicine, 51, 1014-1026. https://doi.org/10.1016/j.freeradbiomed.2010.11.026

[149] Vilella, A., Belletti, D., Sauer, A.K., Hagmeyer, S., Sarowar, T., Masoni, M., Stasiak, N., Mulvihill, J.J.E., Ruozi, B., Forni, F., Vandelli, M.A., Tosi, G., Zoli, M. and Grabrucker, A.M. (2017) Reduced Plaque Size and Inflammation in the APP23 Mouse Model for Alzheimer's Disease after Chronic Application of Polymeric Nanoparticles for CNS Targeted Zinc Delivery. Journal of Trace Elements in Medicine and Biology, 49, 210-221. https://doi.org/10.1016/j.jtemb.2017.12.006

[150] Zhang, L., Reyes, A. and Wang, X. (2018) The Role of Mitochondria-Targeted Antioxidant MitoQ in Neurodegenerative Disease. Molecular and Cellular Therapies, 6, 1-12. https://doi.org/10.26781/2052-8426-2018-01 
[151] Mcmanus, M.J., Murphy, M.P. and Franklin, J.L. (2011) The Mitochondria-Targeted Antioxidant MitoQ Prevents Loss of Spatial Memory Retention and Early Neuropathology in a Transgenic Mouse Model of Alzheimer's Disease. The Journal of Neuroscience, 31, 15703-15715. https://doi.org/10.1523/JNEUROSCI.0552-11.2011

[152] Zhang, C., Zhou, Q., Wu, X., Huang, Y., Zhou, J., Lai, Z., Wu, Y. and Luo, H. (2018) Discovery of Novel PDE9A Inhibitors with Antioxidant Activities for Treatment of Alzheimer's Disease. Journal of Enzyme Inhibition and Medicinal Chemistry, 33, 260-270. https://doi.org/10.1080/14756366.2017.1412315

[153] Diniz, L.P., Tortelli, V., Matias, I., Morgado, J., Bérgamo Araujo, A.P., Melo, H.M., Seixas da Silva, G.S., Alves-Leon, S.V., de Souza, J.M., Ferreira, S.T., De Felice, F.G. and Gomes, F.C.A. (2017) Astrocyte Transforming Growth Factor Beta 1 Protects Synapses against A $\beta$ Oligomers in Alzheimer's Disease Model. Journal of Neurosciences, 37, 6797-6809. https://doi.org/10.1523/JNEUROSCI.3351-16.2017

[154] Yu, L., Liu, Y., Jin, Y., Cao, X., Chen, J., Jin, J., Gu, Y., Bao, X., Ren, Z., Xu, Y. and Zhu, X. (2018) Lentivirus-Mediated HDAC3 Inhibition Attenuates Oxidative Stress in APPswe/PS1dE9 Mice. Journal of Alzheimer's Disease, 61, 1411-1424. https://doi.org/10.3233/JAD-170844

[155] Goldberg, J., Currais, A., Prior, M., Fischer, W., Chiruta, C., Ratliff, E., Daugherty, D., Dargusch, R., Finley, K., Esparza-Moltó, P.B., Cuezva, J.M., Maher, P., Petrascheck, M. and Schubert, D. (2018) The Mitochondrial ATP Synthase Is a Shared Drug Target Foraging and Dementia. Aging Cell, 17, 12715-12728.

https://doi.org/10.1111/acel.12715

[156] Xu, Y.X., Wang, H., Li, X.K., Dong, S.N., Liu, W.W., Gong, Q., Wang, T.D., Tang, Y., Zhu, J., Li, J., Zhang, H.Y. and Mao, F. (2018) Discovery of Novel Propargylamine-Modified 4-Aminoalkyl Imidazole Substituted Pyrimidinylthiourea Derivatives as Multifunctional Agents for the Treatment of Alzheimer's Disease. European Journal of Medicinal Chemistry, 143, 33-47. https://doi.org/10.1016/j.ejmech.2017.08.025

[157] Kumar, B., Sheetal Mantha, A.K. and Kumar, V. (2018) Synthesis, Biological Evaluation and Molecular Modeling Studies of Phenyl-/Benzhydrylpiperazine Derivatives as Potential MAO Inhibitors. Bioorganic Chemistry, 77, 252-262. https://doi.org/10.1016/j.bioorg.2018.01.020

[158] Birnbaum, J.H., Wanner, D., Gietl, A.F., Saake, A., Kundig, T.M., Hock, C., Nitsch, R.M. and Tackenberg, C. (2018) Oxidative Stress and Altered Mitochondrial Protein Expression in the Absence of Amyloid- $\beta$ and Tau Pathology in iPSC-Derived Neurons from Sporadic Alzheimer's Disease Patients. Stem Cell Research, 27, 121-130. https://doi.org/10.1016/j.scr.2018.01.019

[159] Delrieu, J., Ousset, P.J., Voisin, T. and Vellas, B. (2014) Amyloid Beta Peptide Immunotherapy in Alzheimer Disease. Revista de Neurologia, 170, 739-748. https://doi.org/10.1016/j.neurol.2014.10.003

[160] Gibbons, G.S., Banks, R.A., Kim, B., Changolkar, L., Riddle, D.M., Leight, S.N., Irwin, D.J., Trojanowski, J.Q. and Lee, V.M.Y. (2018) Detection of Alzheimer Disease (AD)-Specific Tau Pathology in AD and NonAD Tauopathies by Immunohistochemistry with Novel Conformation-Selective Tau Antibodies. Journal of Neuropathology and Experimental Neurology, 77, 216-228. https://doi.org/10.1093/jnen/nly010

[161] Lo Cascio, F. and Kayed, R. (2018) Azure C Targets and Modulates Toxic Tau Oligomers. ACS Chemical Neuroscience, 9, 1317-1326. 
https://doi.org/10.1021/acschemneuro.7b00501

[162] Tiernan, C.T., Mufson, E.J., Kanaan, N.M. and Counts, S.E. (2018) Tau Oligomer Pathology in Nucleus Basalis Neurons during the Progression of Alzheimer Disease. Journal of Neuropathology and Experimental Neurology, 77, 246-259. https://doi.org/10.1093/jnen/nlx120

[163] Yang, C.C., Chiu, M.J., Chen, T.F., Chang, H.L., Liu, B.H. and Yang, S.Y. (2018) Assay of Plasma Phosphorylated Tau Protein (Threonine 181) and Total Tau Protein in Early-Stage Alzheimer's Disease. Journal of Alzheimer's Disease, 61, 1323-1332. https://doi.org/10.3233/JAD-170810

[164] Jung, H.A., Karki, S., Kim, J.H. and Choi, J.S. (2015) BACEl and Cholinesterase Inhibitory Activities of Nelumbo nucifera Embryos. Archives of Pharmacal Research, 38, 1178-1187. https://doi.org/10.1007/s12272-014-0492-4

[165] Bhakta, H.K., Park, C.H., Yokozawa, T., Min, B.S., Jung, H.A. and Choi, J.S. (2016) Kinetics and Molecular Docking Studies of Loganin, Morroniside and 7-O-Galloyl-D-Sedoheptulose Derived from Corni fructus as Cholinesterase and P-Secretase 1 Inhibitors. Archives of Pharmacal Research, 39, 794-805. https://doi.org/10.1007/s12272-016-0745-5

[166] Choi, R.J., Roy, A., Jung, H.J., Ali, M.Y., Min, B.S., Park, C.H., Yokozawa, T., Fan, T.P., Choi, J.S. and Jung, H.A. (2016) BACEl Molecular Docking and Anti-Alzheimer's Disease Activities of Ginsenosides. Journal of Ethnopharmacology, 190, 219-230. https://doi.org/10.1016/j.jep.2016.06.013

[167] Liu, F., Dong, B., Yang, X., Yang, Y., Zhang, J., Jin, D.Q., Ohizumi, Y., Lee, D., Xu, J. and Guo, Y. (2018) NO Inhibitors Function as Potential Anti-Neuroinflammatory Agents for $\mathrm{AD}$ from the Flowers of Inula japonica. Bioorganic Chemistry, 77, 168-175. https://doi.org/10.1016/j.bioorg.2018.01.009

[168] Chen, C., Li, X., Gao, P., Tu, Y., Zhao, M., Li, J., Zhang, S. and Liang, H. (2015) Baicalin Attenuates Alzheimer-Like Pathological Changes and Memory Deficits Induced by Amyloid $\beta 1-42$ Protein. Metabolic Brain Disease, 30, 537-544. https://doi.org/10.1007/s11011-014-9601-9

[169] Van Gijsel-Bonnello, M., Baranger, K., Benech, P., Rivera, S., Khrestchatisky, M., de Reggi, M. and Gharib, B. (2017) Metabolic Changes and Inflammation in Cultured Astrocytes from the 5xFAD Mouse Model of Alzheimer's Disease: Alleviation by Pantethine. PLoS ONE, 13, e0194586. https://doi.org/10.1371/journal.pone.0175369

[170] Morello, M., Landel, V., Lacassagne, E., Baranger, K., Annweiler, C., Féron, F. and Millet, P. (2018) Vitamin D Improves Neurogenesis and Cognition in a Mouse Model of Alzheimer's Disease. Molecular Neurobiology, 55, 6463-6479. https://doi.org/10.1007/s12035-017-0839-1

[171] Hersh, D.S., Anastasiadis, P., Mohammadabadi, A., Nguyen, B.A., Guo, S., Winkles, J.A., Kim, A.J., Gullapalli, R., Keller, A., Frenkel, V. and Woodworth, G.F. (2018) MR-Guided Transcranial Focused Ultrasound Safely Enhances Interstitial Dispersion of Large Polymeric Nanoparticles in the Living Brain. PLoS ONE, 13, e0192240. https://doi.org/10.1371/journal.pone.0192240

[172] Nuovo, G., Amann, V., Williams, J., Vandiver, P., Quinonez, M., Fadda, P., Paniccia, B., Mezache, L. and Mikhail, A. (2018) Increased Expression of Importin- $\beta$, Exportin-5 and Nuclear Transportable Proteins in Alzheimer's Disease Aids Anatomic Pathologists in Its Diagnosis. Annals of Diagnostic Pathology, 32, 10-16. https://doi.org/10.1016/j.anndiagpath.2017.08.003

[173] González-Ramírez, M., Gavilán, J., Silva-Grecchi, T., Cajas-Madriaga, D., Triviño, S., Becerra, J., Saez-Orellana, F., Pérez, C. and Fuentealba, J. (2018) A Natural Ben- 
zofuran from the Patagonic Aleurodiscus Vitellinus Fungus Has Potent Neuroprotective Properties on a Cellular Model of Amyloid- $\beta$ Peptide Toxicity. Journal of Alzheimer's Disease, 61, 1463-1475. https://doi.org/10.3233/JAD-170958

[174] Paley, E.L., Merkulova-Rainon, T., Faynboym, A., Shestopalov, V.I. and Aksenoff, I. (2018) Geographical Distribution and Diversity of Gut Microbial NADH: Ubiquinone Oxidoreductase Sequence Associated with Alzheimer's Disease. Journal of Alzheimer's Disease, 61, 1531-1540. https://doi.org/10.3233/JAD-170764

[175] Shen, Y., Tian, M., Zheng, Y., Gong, F., Fu, A.K.Y. and Ip, N.Y. (2016) Stimulation of the Hippocampal POMC/MC4R Circuit Alleviates Synaptic Plasticity Impairment in an Alzheimer's Disease Model. Cell Reports, 17, 1819-1831. https://doi.org/10.1016/j.celrep.2016.10.043

[176] Kokras, N., Stamouli, E., Sotiropoulos, I., Katirtzoglou, E.A., Siarkos, K.T., Dalagiorgou, G., Alexandraki, K.I., Coulocheri, S., Piperi, C. and Politis, A.M. (2018) Acetyl Cholinesterase Inhibitors and Cell-Derived Peripheral Inflammatory Cytokines in Early Stages of Alzheimer's Disease. Journal of Clinical Psychopharmacology, 38, 138-143. https://doi.org/10.1097/JCP.0000000000000840

[177] Wang, S., Zhang, X., Zhai, L., Sheng, X., Zheng, W., Chu, H. and Zhang, G. (2018) Atorvastatin Attenuates Cognitive Deficits and Neuroinflammation Induced by A $\beta$ 1-42 Involving Modulation of TLR4/TRAF6/NF- $\kappa$ B Pathway. Journal of Molecular Neuroscience, 64, 363-373. https://doi.org/10.1007/s12031-018-1032-3

[178] Liu, J. and Wang, M. (2018) Carvedilol Protection against Endogenous A $\beta$-Induced Neurotoxicity in N2a Cells. Cell Stress Chaperones, 23, 695-702. https://doi.org/10.1007/s12192-018-0881-6

[179] Hu, X., Song, C., Fang, M. and Li, C. (2018) Simvastatin Inhibits the Apoptosis of Hippocampal Cells in a Mouse Model of Alzheimer's Disease. Experimental and Therapeutic Medicine, 15, 1795-1802. https://doi.org/10.3892/etm.2018.6057

[180] Batista, A.F., Forny-Germano, L., Clarke, J.R., Lyra, E., Silva, N.M., Brito-Moreira, J., Boehnke, S.E., Winterborn, A., Coe, B.C., Lablans, A., Vital, J.F., Marques, S.A., Martinez, A.M.B., Gralle, M., Holscher, C., Klein, W.L., Houzel, J.C., Ferreira, S.T., Munoz, D.P. and De Felice, F.G. (2018) The Diabetes Drug Liraglutide Reverses Cognitive Impairment in Mice and Attenuates Insulin Receptor and Synaptic Pathology in a Non-Human Primate Model of Alzheimer's Disease. Journal of Pathology, 245, 85-100. https://doi.org/10.1002/path.5056

[181] Fu, A.K., Hung, K.W., Huang, H., Gu, S., Shen, Y., Cheng, E.Y., Ip, F.C., Huang, X., Fu, W.Y. and Ip, N.Y. (2014) Blockade of EphA4 Signaling Ameliorates Hippocampal Synaptic Dysfunctions in Mouse Models of Alzheimer's Disease. Proceedings of the National Academy of Sciences of the United States of America, 111, 9959-9964. https://doi.org/10.1073/pnas.1405803111

[182] Zimmermann, G.R., Lehár, J. and Keith, C.T. (2007) Multi-Target Therapeutics: When the Whole Is Greater than the Sum of the Parts. Drug Discovery Today, 12, 34-42. https://doi.org/10.1016/j.drudis.2006.11.008

[183] Millan, M.J. (2006) Multi-Target Strategies for the Improved Treatment of Depressive States: Conceptual Foundations and Neuronal Substrates, Drug Discovery and Therapeutic Application. Pharmacology and Therapeutics, 110, 135-370. https://doi.org/10.1016/j.pharmthera.2005.11.006

[184] Zhu, Y., Xiao, K., Ma, L., Xiong, B., Fu, Y., Yu, H., Wang, W., Wang, X., Hu, D., Peng, H., Li, J., Gong, Q., Chai, Q., Tang, X., Zhang, H., Li, J. and Shen, J. (2009) Design, Synthesis and Biological Evaluation of Novel Dual Inhibitors of Acetylcholinesterase and Beta-Secretase. Bioorganic and Medicinal Chemistry, 17, 1600-1613. 
https://doi.org/10.1016/j.bmc.2008.12.067

[185] Rosini, M., Andrisano, V., Bartolini, M., Bolognesi, M.L., Hrelia, P., Minarini, A., Tarozzi, A. and Melchiorre, C. (2005) Rational Approach to Discover Multipotent Anti-Alzheimer Drugs. Journal of Medicinal Chemistry, 48, 360-363. https://doi.org/10.1021/jm049112h

[186] Liu, H., Liang, F., Su, W., Wang, N., Lv, M., Li, P., Pei, Z., Zhang, Y., Xie, X.Q., Wang, L. and Wang, Y. (2013) Lifespan Extension by $n$-Butanol Extract from Seed of Platycladus orientalis in Caenorhabditis elegans. Journal of Ethnopharmacology, 147, 366-372. https://doi.org/10.1016/j.jep.2013.03.019

[187] Chu, H., Zhang, A., Han, Y., Lu, S., Kong, L., Han, J., Liu, Z., Sun, H. and Wang, X. (2016) Metabolomics Approach to Explore the Effects of Kai-Xin-San on Alzheimer's Disease Using UPLC/ESI-Q-TOF Mass Spectrometry. Journal of Chromatography $B, 1015-1016,50-61$. https://doi.org/10.1016/j.jchromb.2016.02.007

[188] Zhang, A., Sun, H. and Wang, X. (2018) Mass Spectrometry-Driven Drug Discovery for Development of Herbal Medicine. Mass Spectrometry Reviews, 37, 307-320. https://doi.org/10.1002/mas.21529

[189] Wang, L., Ma, C., Wipf, P., Liu, H., Su, W. and Xie, X.Q. (2013) Target Hunter: An in Silico Target Identification Tool for Predicting Therapeutic Potential of Small Organic Molecules Based on Chemogenomic Database. AAPS Journal, 15, 395-406. https://doi.org/10.1208/s12248-012-9449-Z

[190] Liu, H., Wang, L., Lv, M., Pei, R., Li, P., Pei, Z., Wang, Y., Su, W. and Xie, X.Q. (2014) AlzPlatform: An Alzheimer's Disease Domain-Specific Chemogenomics Knowledgebase for Polypharmacology and Target Identification Research. Journal of Cheminformatics, 54, 1050-1060.

[191] Chu, H., Zhang, A., Han, Y. and Wang, X. (2015) Metabolomics and Its Potential in Drug Discovery and Development from TCM. World Journal of Traditional Chinese Medicine, 1, 26-32. https://doi.org/10.15806/j.issn.2311-8571.2015.0022

[192] Zhang, A., Sun, H., Qiu, S. and Wang, X. (2013) Advancing Drug Discovery and Development from Active Constituents of Yinchenhao Tang: A Famous Traditional Chinese Medicine Formula. Journal of Evidence-Based Complementary Alternative Medicine, 2013, Article ID: 257909. https://doi.org/10.1155/2013/257909

[193] Wang, X., Zhang, A., Sun, H., Han, Y. and Yan, G. (2016) Discovery and Development of Innovative Drug from Traditional Medicine by Integrated Chinmedomics Strategies in the Post-Genomic Era. Trends in Analytical Chemistry, 76, 86-94. https://doi.org/10.1016/j.trac.2015.11.010

[194] Zhang, A., Sun, H. and Wang, X. (2014) Potentiating Therapeutic Effects by Enhancing Synergism Based on Active Constituents from Traditional Medicine. Phototherapy Research, 28, 526-533. https://doi.org/10.1002/ptr.5032

[195] Wang, X., Zhang, A., Yan, G., Han Y. and Sun, H.U. (2014) HPLC-MS for the Analytical Characterization of Traditional Chinese Medicines. Trends in Analytical Chemistry, 63, 180-187. https://doi.org/10.1016/j.trac.2014.05.013

[196] Ha, G.T., Wong, R.K. and Zhang, Y. (2011) Huperzine a as Potential Treatment of Alzheimer's Disease: An Assessment on Chemistry, Pharmacology, and Clinical Studies. Chemistry and Biodiversity, 8, 1189-1204. https://doi.org/10.1002/cbdv.201000269

[197] Liu, Q., Zhang, A., Wang, L., Yan, G., Zhao, H., Sun, H., Zou, S., Han, J., Ma, C.W., Kong, L., Zhou, X., Nan Y. and Wang, X. (2016) High-Throughput Chinmedomics-Based Prediction of Effective Components and Targets from Herbal Medicine AS1350. Scientific Reports, 6, Article No. 38437. https://doi.org/10.1038/srep38437 
[198] Wang, X., Zhang, A., Zhou, X., Liu, Q., Nan, Y., Guan, Y., Kong, L., Han, Y., Sun, H. and Yan, G. (2016) An Integrated Chinmedomics Strategy for Discovery of Effective Constituents from Traditional Herbal Medicine. Scientific Reports, 6, Article No. 18997. https://doi.org/10.1038/srep18997

[199] Zhou, X.H., Zhang, A.H., Wang, L., Tan, Y.L., Guan, Y., Han, Y., Sun, H. and Wang, X.J. (2016) Novel Chinmedomics Strategy for Discovering Effective Constituents from ShenQiWan Acting on ShenYangXu Syndrome. Chinese Journal of Natural Medicine, 14, 561-581. https://doi.org/10.1016/S1875-5364(16)30067-X

[200] Zhang, A.H., Sun, H., Yan, G.L., Wang, P., Han, Y. and Wang, X.J. (2015) Chinmedomics: A New Strategy for Research of Traditional Chinese Medicine. Journal of Chinese Mater Medicine, 40, 569-576.

[201] Wang, X.J., Zhang, A.H., Sun, H. and Yan, G.L. (2016) Chinmedomics: Newer Theory and Application. Chinese Herbal Medicine, 8, 299-307.

https://doi.org/10.1016/S1674-6384(16)60055-2

[202] Zhang, A., Liu, Q., Zhao, H., Zhou, X., Sun, H., Nan, Y., Zou, S., Ma, C.W. and Wang, X. (2016) Phenotypic Characterization of Nanshi Oral Liquid Alters Metabolic Signatures during Disease Prevention. Scientific Reports, 6, Article No. 19333. https://doi.org/10.1038/srep19333

[203] Wilkins, J.M. and Trushina, E. (2018) Application of Metabolomics in Alzheimer's Disease. Frontiers in Neurology, 8, 719-739. https://doi.org/10.3389/fneur.2017.00719

[204] Ide, K., Matsuoka, N. and Kawakami, K. (2018) Is the Use of Proton-pump Inhibitors a Risk Factor for Alzheimer's Disease? Molecular Mechanisms and Clinical Implications. Current Medicinal Chemistry, 25, 2166-2174. https://doi.org/10.2174/0929867325666180129101049

[205] Coman, H. and Nemes, B. (2017) New Therapeutic Targets in Alzheimer's Disease. International Journal of Gerontology, 11, 2-6. https://doi.org/10.1016/j.ijge.2016.07.003

[206] Airoldi, C., La Ferla, B., D’Orazio, G., Ciaramelli, C. and Palmioli, A. (2018) Flavonoids in the Treatment of Alzheimer's and Other Neurodegenerative Diseases. Current Medicinal Chemistry, 25, 3228-3246. https://doi.org/10.2174/0929867325666180209132125 